\title{
Large-Eddy Simulations of Real-World Episodes in Complex Terrain Based on ERA-Reanalysis and Validated by Ground-Based Remote Sensing Data
}

\author{
CORnelius Hald, MatThias ZeEman, PATRICK LauX, \\ MATTHIAS MAUDER, AND HARALD KUNSTMANN ${ }^{\mathrm{a}}$ \\ Institute of Meteorology and Climate Research (IMK-IFU), Karlsruhe Institute of Technology, \\ Garmisch-Partenkirchen, Germany
}

(Manuscript received 16 January 2019, in final form 28 August 2019)

\begin{abstract}
A computationally efficient and inexpensive approach for using the capabilities of large-eddy simulations (LES) to model small-scale local weather phenomena is presented. The setup uses the LES capabilities of the Weather Research and Forecasting Model (WRF-LES) on a single domain that is directly driven by reanalysis data as boundary conditions. The simulated area is an example for complex terrain, and the employed parameterizations are chosen in a way to represent realistic conditions during two 48-h periods while still keeping the required computing time around $10^{5}$ CPU hours. We show by evaluating turbulence characteristics that the model results conform to results from typical LES. A comparison with ground-based remote sensing data from a triple Doppler-lidar setup, employed during the "ScaleX" campaigns, shows the grade of adherence of the results to the measured local weather conditions. The representation of mesoscale phenomena, including nocturnal low-level jets, strongly depends on the temporal and spatial resolution of the meteorological boundary conditions used to drive the model. Small-scale meteorological features that are induced by the terrain, such as katabatic flows, are present in the simulated output as well as in the measured data. This result shows that the four-dimensional output of WRF-LES simulations for a real area and real episode can be technically realized, allowing a more comprehensive and detailed view of the micrometeorological conditions than can be achieved with measurements alone.
\end{abstract}

\section{Introduction}

Large-eddy simulation (LES) is a tool for studying turbulent motions in the atmosphere. By using a model resolution of $100 \mathrm{~m}$ or smaller, the large turbulent motions can be explicitly resolved. This part of the turbulence represents the inertial subrange (e.g., Stull 1988), a range in which the turbulent energy is passed on from larger to smaller eddies. All structures smaller than a certain filter width, usually dependent on the model resolution, are parameterized in an LES, assuming that turbulence on very small scales is close to being isotropic, a prerequisite for the application of a parameterization. A subgrid-scale model is responsible for the representation of all turbulent motions smaller than the filter and the dissipation of kinetic energy into heat.

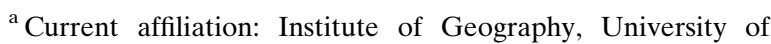
Augsburg, Augsburg, Germany.
}

Corresponding author: Cornelius Hald, cornelius.hald@kit.edu
LES have been used since around 1970 (Deardorff 1970), starting with the application of such models to neutral (Deardorff 1972; Andren et al. 1994; Beare et al. 2006) or convective (Moeng 1984, 1986; Nieuwstadt et al. 1993; Siebesma et al. 2003) boundary layers because of the relatively large size of the turbulent motions under those conditions. With growing access to extensive computing resources and the ability to improve the resolutions in LES to resolve turbulence on the smallest scale, studies for stable boundary layers were conducted (Kosović and Curry 2000; Saiki et al. 2000; Basu and Porté-Agel 2006; Huang and Bou-Zeid 2013). Most of these applications of LES used idealized initial and boundary conditions, representing flat and homogeneous or regularly patched surfaces (Bou-Zeid et al. 2004) or ideal valleys (Wagner et al. 2015). Moreover, the meteorological drivers were mostly idealized and periodic, with constant winds or prescribed temperature profiles.

In recent years, LES studies with real-world conditions have emerged. In contrast to the studies of flat and 
homogeneous terrain listed above, these try to approach nonidealized conditions: they use nonflat surfaces, changing heat fluxes, wind speeds or temperature profiles. Some examples are the examination of a flow over a realistic hill (Chow and Street 2009), the transition from a stable to a convective boundary layer in the morning hours (Beare 2008) or the flow over urban structures (Bou-Zeid et al. 2009). The studies listed up to this point use model systems specifically designed as large-eddy simulation frameworks. They often lack the capabilities of weather models, especially in the area of nesting and specifying boundary and initial conditions to represent real weather conditions at certain locations.

The study presented here uses the LES capabilities of the Weather Research and Forecasting (WRF) Model (WRF-LES; Skamarock et al. 2008). Some applications of WRF-LES are, for example, the simulation of a daytime boundary layer in an idealized valley (Catalano and Moeng 2010) or a neutral boundary layer (Hattori et al. 2010), the simulation of the sea breeze (Crosman and Horel 2012) or the evaluation of the transport of passive tracer gases around a solitary hill (Nunalee et al. 2014) and of pollutants over a mountain range (Lang et al. 2015). The effects of nesting an LES domain in another was described by Moeng et al. (2007) and Mirocha et al. (2013). Muñoz-Esparza et al. (2014a) nest an LES representing a convective maritime boundary layer in an ideal LES. Nesting of LES in a mesoscale simulation is described in Mirocha et al. (2014). Aitken et al. (2014) present a module for the representation of wind turbines that can be used in WRF-LES, Chu et al. (2014) and Xue et al. (2016) evaluate how silver iodide is spread when released in the atmosphere.

While the idealized LES were mostly performed for investigations of the structure of turbulence in the atmosphere and for improving the boundary layer parameterizations in mesoscale models, LES for realistic conditions serve a different purpose: if the LES results are proven to sufficiently represent the real conditions at the simulated location, they provide a realistic fourdimensional picture of the flow structures. Therefore, LES can be a helpful addition to the interpretation of spatially sparse observational data. Observational stations are often confined to few stationary locations, hence do not collect dense information in space, whereas moving measurement platforms (e.g., planes and drones) can gain spatial information, on the expense of the temporal information. Model data have information in all dimensions.

Because of its origin as a mesoscale weather and climate model, WRF already has many parameterizations and submodels implemented. WRF additionally comes with a preprocessing system ("WPS") for providing boundary conditions.

Realistic conditions in a weather model are approximated when the model simulates the diurnal changes to radiation, when it uses information on land use, land cover and elevation, when moisture in the air is considered and when the boundary conditions represent real weather. This is costly in WRF-LES: every module that is switched on in addition to the fluid dynamics computations increases the required computing time significantly. Until now, only few studies on such realistic conditions with WRF-LES have been performed; examples include Talbot et al. (2012), who evaluate the influence of different resolutions on the results for an LES of an urban area and Rai et al. (2017), who simulated a rural area in the northwestern United States and compared model outcomes to measurements. Muñoz-Esparza et al. (2017) nested realistic LES domains in three mesoscale domains and compared model outcomes to measurements.

In this study, we use WRF-LES to simulate two realworld episodes over complex terrain, characterized by height differences of $440 \mathrm{~m}$, slopes of up to $20^{\circ}$, and varying soil properties that influence friction and the heat and moisture fluxes. The area is an example for a place dominated by agriculture in the temperate regions of central Europe. Studying complex terrain is necessary to allow a wider range of opportunities for LES in realworld micrometeorological investigations. The simulated periods contain the transitions from nocturnal to daytime boundary layers and vice versa. The model results are evaluated against measurements of wind profiles using a triple Doppler-lidar setup.

The first objective of this study is to analyze and evaluate model setups to achieve a stable model run in WRF-LES when using realistic boundary conditions and parameterizations over complex terrain. The second objective is, in its first part, to evaluate if WRF-LES with the computationally efficient configuration presented here (driving the LES domain directly with reanalysis data as boundary conditions) is able to produce results that are representative for an LES. In the second part we show by comparing to virtual tower measurements that WRF-LES is able to reproduce the mean quantities of the wind fields measured. Only typical LES data resolution is high enough that it can resolve the strong variability of wind properties with height and allows for a detailed comparison with measurements that exceeds the simple inspection of averages. As a third objective, we demonstrate how an LES for a known area is a valuable addition to measurements, by analyzing possible reasons for the phenomenon of a measured spike in wind speed. The four-dimensional model output shows 
the origin and development of the flow due to the influence of the terrain and therefore allows a much deeper insight in the local meteorological conditions compared to the measurements alone. This is not possible with weather models in mesoscale resolution, yet this configuration of WRF-LES is able to produce the detail necessary while using about one order of magnitude less in processing power than nested simulations.

Section 2 contains the setup of the WRF-LES model and information about the measurement principles of the Doppler lidar. Section 3 describes and discusses the results of the simulations and the grade of agreement between model and measurements and shows how realistic LES can complement measurements. The article ends with the conclusions in section 4 .

\section{Methods}

\section{a. Model setup}

The WRF Model (Skamarock et al. 2008) has its origin in simulating the weather and climate for the macro and mesoscale for operational and research purposes. It contains a refined preprocessing system (WPS) with the ability to create input and boundary files representing realistic conditions. It offers parameterizations for microphysics, radiation and land surface processes and also the possibility of nesting. Many of these can also be applied when running WRF in LES mode. Version 3.7.1 of the model code was used. It was run in a single domain configuration. The domain covers $15 \mathrm{~km}$ by $15 \mathrm{~km}$ with 500 grid points in the $x$ and $y$ directions, meaning $\Delta x=$ $\Delta y=30 \mathrm{~m}$. In the $z$ direction the model reaches up to $500 \mathrm{hPa}$ at approximately $5500 \mathrm{~m}$ above mean sea level (MSL) and is split into 150 vertical levels. The height intervals are unevenly distributed: the first 105 levels have a resolution of approximately $11 \mathrm{~m}$. Above this point, the vertical resolution becomes coarser with height, reaching approximately $100 \mathrm{~m}$ at level 130 and approximately $150 \mathrm{~m}$ at the topmost level. The radiation model uses additional levels during runtime to include any radiative effects above $500 \mathrm{hPa}$. The variability in the heights of the vertical levels results from WRF's pressure based vertical levels and the terrain following coordinates. Because of the complexity of the terrain surrounding the area of interest it was not possible to find model configurations that nest the LES domain into other LES domains (e.g., following Talbot et al. 2012) or in mesoscale domains with parameterized boundary layers (e.g., following Rai et al. 2017). The vertical resolution of $11 \mathrm{~m}$ would have led to high aspect ratios between $\Delta x$ and $\Delta z$, which through high slope angles could lead to model instabilities (Lundquist et al. 2010).
The vertical nesting in WRF (Daniels et al. 2016), officially implemented in version 3.8 of the model code, could already be used in 3.7.1, but because of limitations concerning the available parameterizations when nesting vertically, this approach was not pursued further here.

Within the top $500 \mathrm{~m}$ of the model domain, there is a Rayleigh damping layer to prevent the reflection of waves from the upper domain boundary, including the sound waves originating from the compressible form of the equations of motion (Moeng et al. 2007). Many other LES codes apply the Boussinesq and anelastic approximations to simplify the equations.

The simulation included the periods 15-17 July 2015 and 6-8 July 2016. Both 48-h periods were selected because they both were times of high incoming solar radiation with moderate geostrophic winds, meaning that the turbulent structures during the day are large and the exchange processes are mostly driven by buoyancy. No precipitation was observed during the dates and in the selected study area.

The model domain was initialized with atmospheric boundary conditions taken directly from the ERA interim reanalysis (ECMWF 2009, updated monthly). This dataset is in T255 horizontal resolution, spanning about $0.7^{\circ}$. That means that the input data created by WPS for a $15 \mathrm{~km} \times 15 \mathrm{~km}$ domain are practically taken from a single grid point in the reanalysis. Because of the interpolation routines used by WPS for the meteorological input, there are gradients present in the initial and boundary conditions. Both are additionally modified by the high-resolution terrain in the domain, introducing further variability. Meteorological boundary conditions were updated every $6 \mathrm{~h}$.

Land-use classification data are taken from the 28-category "Corine" land-use dataset in 3-arc-s resolution (CLC 2000). The digital elevation model (DEM) is taken from the 1-arc-s Advanced Spaceborne Thermal Emission and Reflection Radiometer (ASTER) dataset (National Aeronautics and Space Administration and Japan's Ministry of Economy Trade and Industry 2009).

The domain is centered around $47.823^{\circ} \mathrm{N}$ and $11.079^{\circ} \mathrm{E}$ and is located in southern Germany (Fig. 1a). Within the domain the elevation ranges from 520 to $960 \mathrm{~m}$ MSL (Fig. 1b). The eastern part is characterized by relatively flat terrain. To the west, a plateau rising the terrain to above $700 \mathrm{~m}$ can be found. On the southern part of the plateau lies a mountain with a maximum height of $962 \mathrm{~m}$, followed by a narrow valley in the southwestern part of the domain. Further information on the area can be found in Wolf et al. (2017). The eastern flank of the mountain, which is coinciding with the ridge, leads to a 

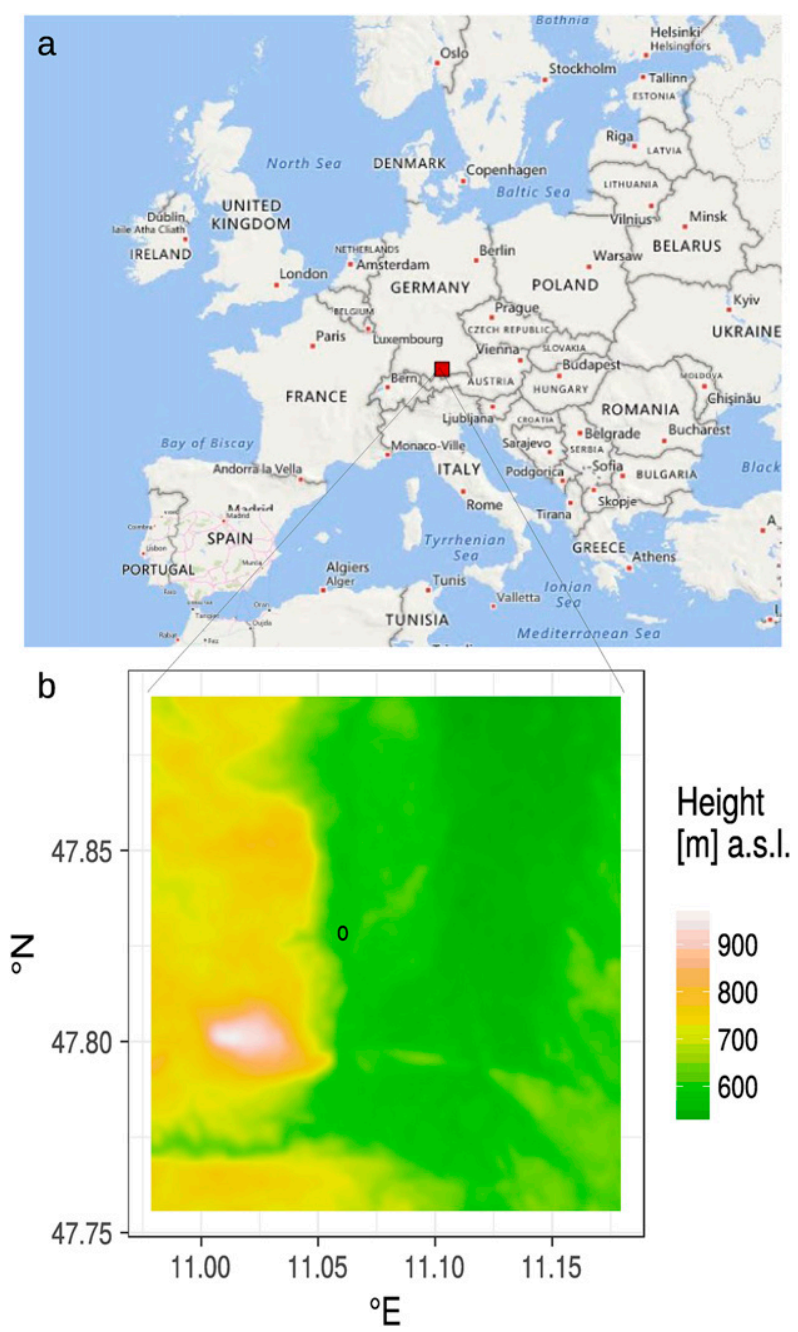

FIG. 1. (a) The position of the model domain in Europe (source: Bing Maps). (b) The orography (m MSL) of the modeled area. The open circle shows the position of the virtual tower.

steep slope in the terrain. Angles of about $30^{\circ}$ in connection with WRF's terrain following coordinates result in numerical instabilities (Lundquist et al. 2010). The DEM therefore was smoothed until the maximum slope angles were at $20^{\circ}$. The black circle in Fig. $1 \mathrm{~b}$ shows the location of the virtual tower device. The measurements of this device are used for the evaluation of the simulated data (see sections $2 \mathrm{~b}$ and $3 \mathrm{~b}$ for details). It was not possible to center the domain around this location because of a gorge to the immediate west of the domain and mountains to the southwest. These features would have required a very extensive usage of smoothing of the input data that would have meant a great loss of information.

The WRF single-moment five-class microphysics scheme (Hong et al. 2004) was used in combination with the Rapid Radiative Transfer Model for long- and shortwave radiation (Iacono et al. 2008), updated every four model time steps. For a land surface model (LSM), the Noah LSM was used and Monin-Obukhov (MO) similarity governed the exchange between surface and atmosphere. It was described by Basu and Lacser (2017) that MO should not be used if the lowest vertical level is below a multiple of the roughness elements. The lack of alternatives in WRF made its use necessary. To reduce its influence, the lowest model level was not included in the evaluation. The diffusion coefficients were calculated by the 1.5-order turbulence kinetic energy (TKE) closure in three dimensions, and the subgrid processes were parameterized by the Nonlinear Backscatter and Anisotropy (NBA) model with TKE-based stress terms (Kosović 1997; Mirocha et al. 2010).

To achieve a stable model run, an adaptive time step was used. Maximum time steps are 0.25 and $0.2 \mathrm{~s}$ in the 2015 and 2016 model, respectively. The smaller time step for the 2016 episode was necessary because of higher wind speeds during the simulated period. A minimum time step of $0.0625 \mathrm{~s}$ was allowed for both model runs and used only on the first few time steps during initialization. After that, all model time steps were at their prescribed maximum. It has to be noted that the solutions of the presented runs are affected by the dependency on the acoustic and model time step as was presented by Yamaguchi and Feingold (2012). Both model runs were initialized at 0000 UTC (0200 local time) on their respective dates. Data starting at $6 \mathrm{~h}$ after model initialization were deemed usable. Full 3D fields were written every $5 \mathrm{~min}$. The data to be compared with the measurements are taken from profiles at four grid points in a $2 \times 2$ pattern at the measurements' location. These profiles were written at the model time resolution $(0.25$ or $0.2 \mathrm{~s})$ and later averaged in horizontal space and time. Data for the shown spectra of turbulence were treated accordingly.

The resulting modeling system drives a single LES domain directly with boundary conditions derived from the reanalysis data. The absence of any nesting processes lowers the cost in computing time so considerably that it is not outweighed by the use of the parameterizations listed above. One simulation with the described setup over two diurnal cycles took approximately $10^{5}$ CPU hours. Muñoz-Esparza et al. (2017) require an order-of-magnitude more for their complex setup with four nested domains and similar parameterizations. We therefore recommend this modeling approach for cases in which CPU power is sparse. It might also be used for small ensembles, which is usually not done in LES. Shortcomings in this modeling approach are expected in meteorological phenomena originating from the mesoscale: structures 
that are too small to be represented in the boundary conditions but too large to be generated within the LES domain might be neglected.

\section{b. Description of the virtual tower measurements}

Three Doppler lidars (DL; Halo Photonics, Ltd., model StreamLine XP) were placed approximately $500 \mathrm{~m}$ apart in a triangular arrangement. Each DL retrieves the speed of the air along a beam by measuring the Doppler shift in light as it is backscattered by aerosols. All three lidars simultaneously performed a scan along a vertical profile, producing a virtual measurement tower. While a single lidar can only measure speeds toward or away from its location, the combination of three is able to measure all three wind components $(u, v$, and $w)$, where $u$ is the zonal component, $v$ is the meridional component, and $w$ is the vertical wind component (Newman et al. 2016). The wind vectors follow from rotation of the along-thebeam wind vectors observed nearest to an intersection along the virtual profile (Stawiarski et al. 2013; Vasiljević et al. 2017). The points along the vertical profile were chosen to be $3 \mathrm{~m}$ apart up to $20 \mathrm{~m}$ above ground and $18 \mathrm{~m}$ apart up to a height of $1000 \mathrm{~m}$ above ground. The range above a depth of $1000 \mathrm{~m}$ was excluded here because of discontinuous observations farther away from the DLs, following detection limitations that were thought to be related to a decrease in particle density away from the surface that leads to decrease in backscattered laser light signal. The measured values of $w$ in the lowest levels were considered to be unreliable and are therefore excluded from the evaluation. Aggregations in 10, 20, and $30 \mathrm{~min}$ were computed from 1-min DL scans of $1-\mathrm{Hz}$ integration per beam. The DL measurement period overlapping with the simulated period was from 0600 UTC 15 July to 0000 UTC 17 July ( $42 \mathrm{~h}$ ) for the 2015 measurement campaign, which included two sunsets and one whole night. The overlapping period for the 2016 campaign spans $32 \mathrm{~h}$, from 1600 UTC 6 July to 0000 UTC 8 July, covering two sunsets, one sunrise, and one whole night and day. To perform a meaningful comparison, the measured wind speeds were linearly interpolated to the heights of the model levels.

\section{Results and discussion}

\section{a. Instantaneous velocity fields}

Here we evaluate the model results for two distinct cases: Fig. 2 shows the instantaneous values for horizontal and vertical wind speed during a time period with low horizontal wind speeds, 1000 UTC 16 July 2015.
Figures $2 \mathrm{a}$ and $2 \mathrm{~d}$ show the values taken from the ninth model level ( $\approx 100 \mathrm{~m}$ above ground). The plot for the vertical wind speed (Fig. 2d) shows the typical situation for a boundary layer that is driven by buoyancy: spatially small areas with rising air are surrounded by larger patches of downdrafts. These cells of alternating up and downdrafts develop when the ratio between boundary layer height and Obukhov length $\left(z_{i} / L\right)$ is strongly negative. The boundary layer height $z_{i}$ is derived by searching for the largest gradient in the potential temperature (Sullivan et al. 1998). The Obukhov length $L$ is a scaling parameter for the surface layer:

$$
L=\frac{-\overline{\Theta_{v}} u_{*}^{3}}{k g\left(\overline{w^{\prime} \Theta_{v}^{\prime}}\right)_{s}},
$$

where $\Theta_{v}$ is the virtual potential temperature, $u_{*}$ is the friction velocity, $k$ is the von Kármán constant (set to a value of 0.4 in WRF), $g$ is the gravitational constant, and $\overline{w^{\prime} \Theta_{v s}^{\prime}}$ is the kinematic heat flux at the surface. Deardorff (1972) finds cells at $z_{i} / L<-4.5$, and LeMone (1973) finds them at $z_{i} / L<-10$. In the shown case, the bulk of the grid points exhibit values between -10 and -25 . The total range of is from -60 to 0 . Because of the inhomogeneities in terrain and land cover and the changing meteorological drivers, values of $z_{i} / L$ can vary strongly between adjacent grid points. This is in contrast to idealized simulations, in which all grid points are expected to behave equally.

The patterns in Fig. 2 diverge from their ideal cell-like counterparts taken from idealized LES-Models (see e.g., Moeng et al. 2007) because of a horizontal wind speed larger than zero and inhomogeneities in surface properties and elevation. Modifications due to the underlying height gradients can be seen in the southwestern part of the domain where the mountain is located. On the southeastern slope is an accumulation of grid points with rising air (Fig. 2d), possibly resulting from solar radiation coming in at an angle and heating the slope more than the surroundings. The thermals show rising speeds of up to $5 \mathrm{~m} \mathrm{~s}^{-1}$, whereas the sinking air never exceeds $3 \mathrm{~m} \mathrm{~s}^{-1}$.

Figures $2 \mathrm{~b}$ and $2 \mathrm{e}$ show vertical cross sections through the position of the virtual tower from west to east, and Figs. $2 \mathrm{c}$ and $2 \mathrm{f}$ show the same thing but from south to north. Both cuts reveal an area of distinct shear at about $2000 \mathrm{~m}$ MSL. This originates from the reanalysis data used to drive the model, because the simulation cannot produce shear on its own within this domain. It does not coincide with the boundary layer height, which is at approximately $500-700 \mathrm{~m}$ above ground during this time (evaluated by the gradient method applied to a spatial mean of 60 by 
a
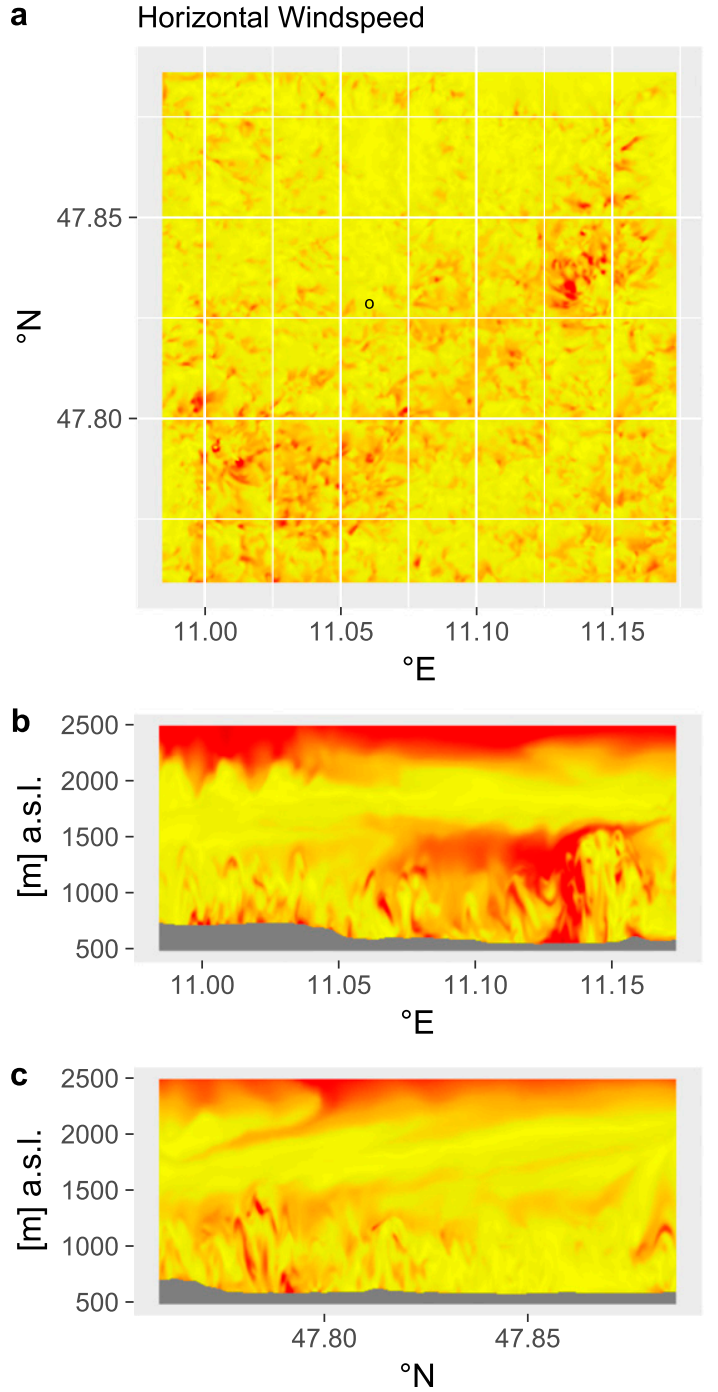

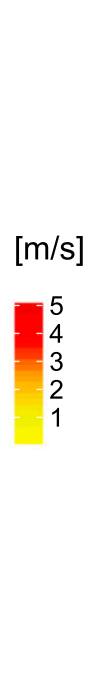

d

d Vertical Windspeed
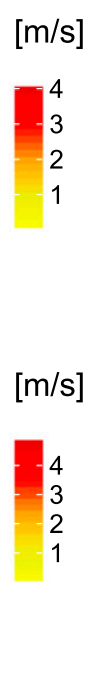
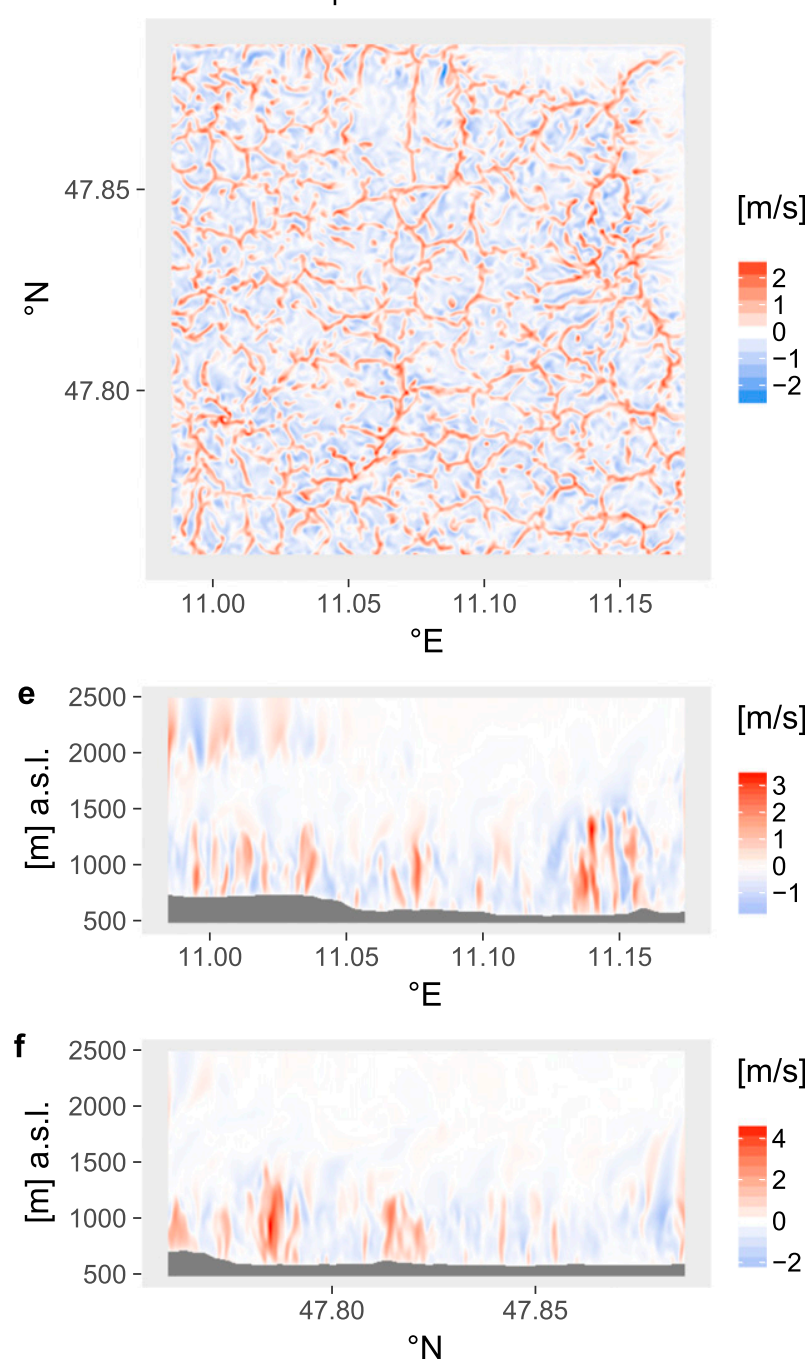

FIG. 2. Instantaneous values of wind components [(left) horizontal wind speed; (right) vertical wind speed] for a time step of low horizontal wind speeds (1000 UTC 16 Jul 2015): (a),(d) values from the ninth vertical model level [ 100 m above ground; the open circle in (a) shows the position of the virtual tower], (b),(e) a cut from west to east through the virtual tower position, and (c),(f) a cut from south to north through the virtual tower position.

60 grid points at every grid point). The upper limit of the boundary layer is at the upper maximum extent of the thermal structures, especially visible in Figs. 2e and $2 \mathrm{f}$.

Figure 3 shows a time of high horizontal wind speeds (1600 UTC 7 July 2016) from a northerly direction. Because WRF does not use any information about turbulence (e.g., vertical wind speeds or TKE) in the meteorological boundary conditions derived for real cases, turbulence has to develop within the domain. If horizontal wind speeds are larger than 0 , this limitation of WRF manifests in areas of underdeveloped turbulence at the inflow edge that can be seen at the inflow edge of the domain, in the case of Figs. 3a and $3 \mathrm{~d}$ at the northern edge. When using WRF in an idealized mode and applying periodic boundary conditions this problem does not arise, but when nesting another domain within the periodic domain it can be noted. Several studies have described this behavior: Mirocha et al. (2013) used one-way nesting in a neutral boundary layer, finding large streaks of underdeveloped turbulence at the inflow boundary, with their extent depending on the subgrid-scale model that was used, the geostrophic wind speed, and the horizontal resolution of the model. They find that the NBA subgrid-scale model used here shows the best results of the ones that are implemented in WRF and that a higher resolution allows for a quicker 
development of turbulence. The size of the area of undeveloped turbulence is dependent on the wind speed: the higher that it is, the larger the area is. Muñoz-Esparza et al. (2014b) find similar characteristics and propose the application of perturbing the temperature fields at the domain edges. This is applied to a realistic case in Muñoz-Esparza et al. (2014a) and to idealized neutral, stable and convective boundary layers in Muñoz-Esparza and Kosović (2018). Note that the authors listed here use geostrophic wind speeds of 5 and $10 \mathrm{~m} \mathrm{~s}^{-1}$ (Mirocha et al. 2013); $10 \mathrm{~m} \mathrm{~s}^{-1}$ (Muñoz-Esparza et al. 2014b); and 5, 10, and $15 \mathrm{~m} \mathrm{~s}^{-1}$ (Muñoz-Esparza and Kosović 2018) as boundary condition. These wind speeds are comparatively high and are responsible for the size of the area of unresolved turbulence. In our case presented here, wind speeds rarely exceed $5 \mathrm{~m} \mathrm{~s}^{-1}$ in the boundary layer [cf. Figs. 7 and 9 (described in more detail below), if one ignores the nocturnal low-level jets that are above the boundary layer]. This limits the size of the area of underdeveloped turbulence to what can be seen in Fig. 3 . Additionally, Mirocha et al. (2014) note that the development of turbulence is favored by the presence of slopes in the domain and a positive heat flux at the surface, both of which exists in the modeling approach presented here.

The extent of the space in which no turbulence is developed can be seen on the right side of Fig. 3c. In this case, with a mean wind speed of $3.4 \mathrm{~m} \mathrm{~s}^{-1}$, it takes about 50 grid points of distance from the inflow edge until turbulence develops near the ground and 150 grid points until turbulence is visible over the whole column. In cases with higher wind speeds, the amount of grid points that it takes until turbulence is developed fully is significantly larger. This has to be considered when setting the size of the model domain.

More information about the validity of the simulations and a sign that turbulence is indeed developed in the domain can be gathered from the spectrum of the frequencies of turbulence in Fig. 4. Here we show the spectra from five different locations in the domain: all are on the same longitude in the center, but on different latitudes. Far north is 50 grid points away from the northern edge, north is 150 grid points from the northern edge, center is in the center of the domain, and south and far south are 350 and 450 grid points of distance from the northern edge, respectively. The data are taken over $2 \mathrm{~h}$ (1500-1700 UTC 7 July 2016), containing the time step shown in Fig. 3. Before performing the Fourier transformation, the data are detrended and tapered by the use of a cosine bell taper to the first and last $10 \%$ of the data, following the instructions in Stull (1988), by using the "spec.taper" function in the R statistics software package. Shown are resolved frequencies in the horizontal wind speed. Only the point closest to the inflow edge shows an underdeveloped spectrum, where only the largest structures are resolved and spectral densities drop at high frequencies. All other points show similarly developed spectra with a distinctive inertial subrange. We therefore argue that the simulation results presented here are valid and can be used further, under the condition that grid points without developed turbulence are omitted from the analysis.

In terms of stability criteria, the period shown in Fig. 3 is different from the one in Fig. 2: Values for $z_{i} / L$ are in the range from 0 to -13 over the whole domain. In contrast to cells forming, these values are within the range shown by LeMone (1973) and Deardorff (1972) to possibly produce roll like structures in the boundary layer. A comprehensive review on these rolls can be found in Etling and Brown (1993). There are elongated structures present in Fig. 3, especially visible in the vertical wind speeds in the eastern part of the domain.

The simulated periods of 2 times $48 \mathrm{~h}$ encompass several states in which the atmospheric boundary layer can be. Instances of strongly and moderately convective periods are shown in Figs. 2 and 3, respectively. Neutral stratification is a theoretical construct that happens very rarely in nature. It can be found at times when the unstable boundary layer turns stable or vice versa. These conditions are present during sunset and sunrise. The stable boundary layer on the other hand occurs in most nights. Stable nocturnal boundary layers are characterized by low wind speeds and a strong negative temperature gradient with height. The stable layering dampens turbulence, the turbulent structures are smaller than during day (e.g., Stull 1988). The smaller the turbulent structures are, the smaller the model resolution has to be to resolve these structures.

Figure 5 shows spectra from times of strongly and moderately convective periods and a night period at the location of the virtual tower. To keep the data comparable, they are in all three cases taken from the 15 vertical levels below the averaged boundary layer height during the time considered. During day, the boundary layer height is determined by using the gradient method. The determination of the nocturnal boundary layer height cannot be accomplished by searching for the largest gradient in the potential temperature, because these gradients are within the boundary layer. Its height is limited by the residual layer above, in which the temperature gradients with height are small. Because there is, to our knowledge, no formal method of determining the height of the nocturnal boundary layer, we define it here as the height in which the gradient in 
a
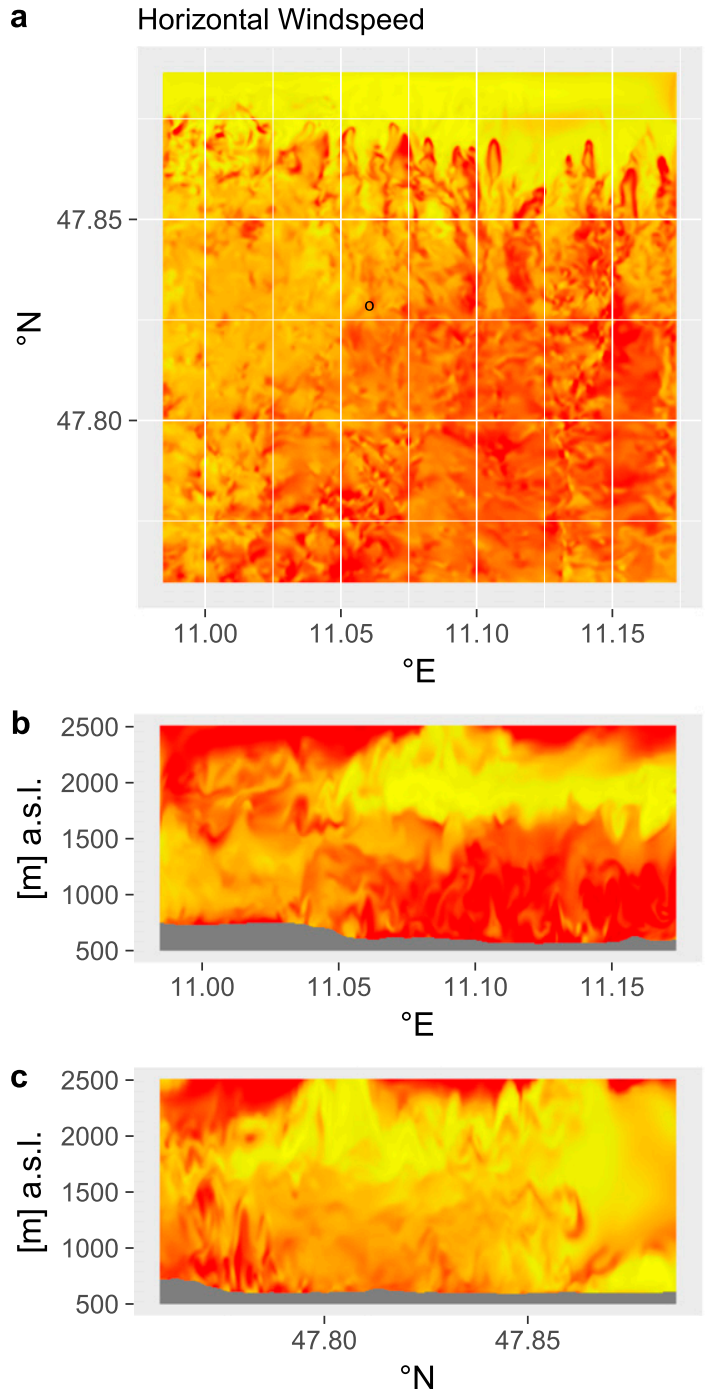

d

$[\mathrm{m} / \mathrm{s}]$

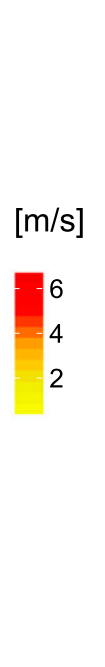

$[\mathrm{m} / \mathrm{s}]$
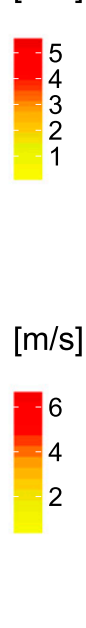

d Vertical Windspeed

$47.85-$

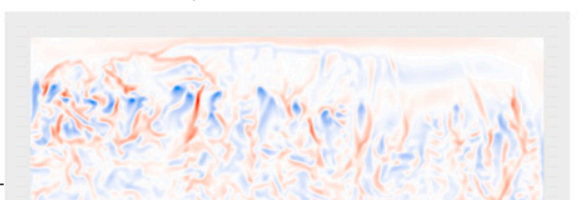

47.80

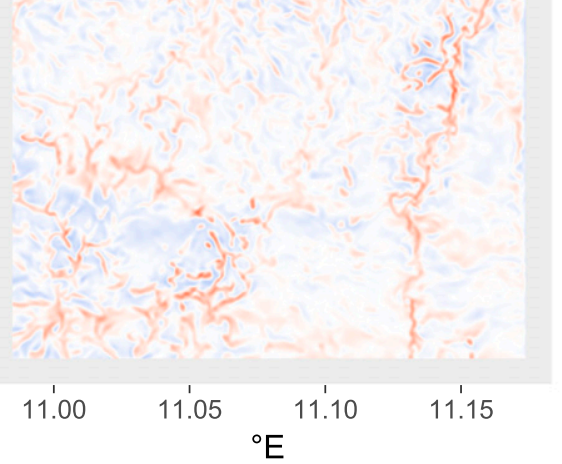

$[\mathrm{m} / \mathrm{s}]$ $=4$
2
0
-2
-4
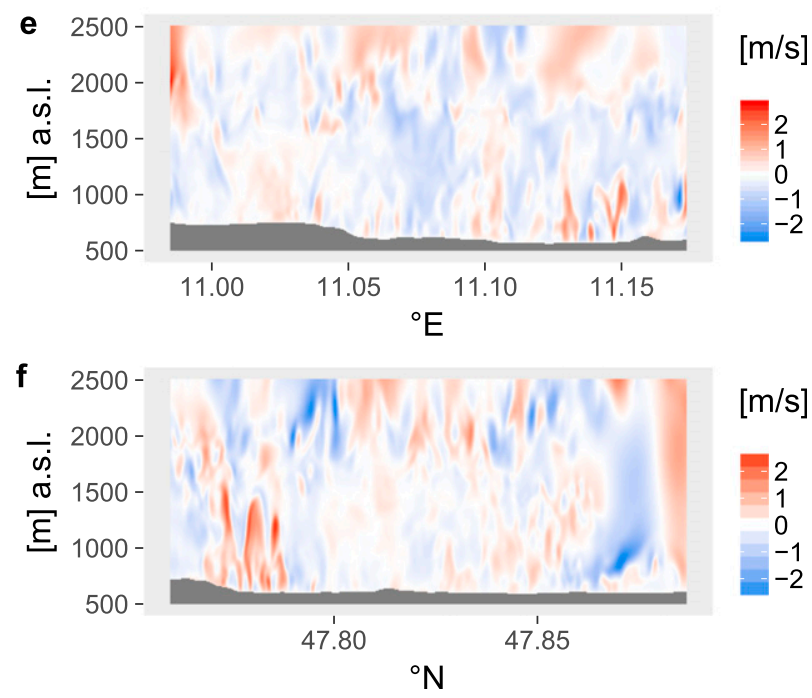

FIG. 3. As in Fig. 2, but for a time step of high horizontal wind speeds (1600 UTC 7 Jul 2016).

potential temperature falls below $5 \%$ of the largest gradient measured beneath.

It is evident that turbulence in the moderately convective case shown in Fig. 5 is best resolved. This is the time shown in Fig. 3, characterized by high horizontal wind speeds. The spectrum for the strongly convective case is less well developed, there is less power on smaller scales. One reason is that turbulent structures that are predominantly caused by buoyancy are comparatively large. Another factor might be that these data are taken from the 2015 simulation that uses a slightly larger time step. Nevertheless, the inertial subrange is developed. During night the spectrum shows some scales of resolved turbulence. The total intensity is lower than in the two other cases, which is to be expected because of the smaller eddies present in the nocturnal boundary layer. An inertial subrange is discernible, but it is smaller than in the other two cases. In all three cases, the intensities in the vertical wind speed are higher than in the horizontal wind. According to Kaimal and Finnigan (1994), a spectrum shows atmospheric turbulence, when an inertial subrange is present and when the ratio in the intensities between streamwise and vertical wind speed in this inertial subrange is $4 / 3$. In our shown case the ratio is always positive but ranges between 1 and 4 . This is because the frequency range of the inertial subrange has to be determined by hand and a small shift gives very different results. We also assume that the fact that the vertical resolution in this simulation is three times as fine as the horizontal resolution leads to more intensity in the vertical portion of the turbulence. We conclude from Fig. 5 that the resolution of our models is sufficient for well-developed turbulence during daytime but may be too coarse to properly resolve nighttime turbulence. 


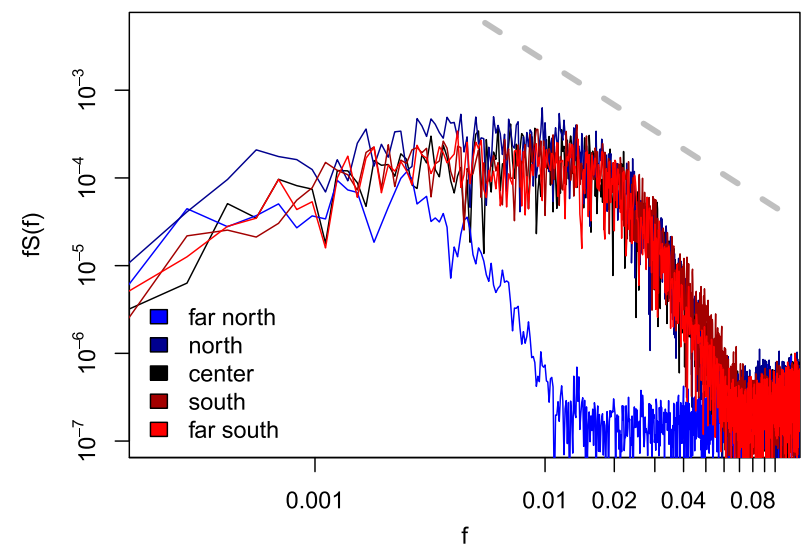

FIG. 4. Spectra of horizontal wind speed at five distances from the northern edge: 50 (far north), 150 (north), 250 (center), 350 (south) and 450 (far south) grid points. Data are taken from $2 \mathrm{~h}$ of model data (1500-1700 UTC 7 Jul 2016) and are averaged over three vertical levels (55-77 $\mathrm{m}$ over ground). The gray dashed line is $f^{-5 / 3}$ and marks the inertial subrange.

\section{b. Comparison with virtual tower measurements}

Figures 6 and 7 show the wind directions and wind speeds in the column above the virtual tower for the model (Figs. 6a and 7a) and the measurements (Figs. 6b and 7b) in 2015. The directions were calculated from the meridional and zonal wind components, averaged over $10 \mathrm{~min}$. Both figures only contain the time steps at which data are available for both the model and the virtual tower. Dotted vertical lines mark the timing of the sunset; dashed lines mark the sunrise.

The comparable period in 2015 contains $42 \mathrm{~h}$ spanning from 0600 UTC 15 July to 0000 UTC 17 July. The first day, according to the measurements, is characterized by a well-mixed daytime boundary layer with winds coming from northeast. These conditions are reached in the model by about 1500 UTC. Before that, the model shows an area of shear rising from the ground at 1000 UTC up to $1250 \mathrm{~m} \mathrm{MSL}$ at 1500 UTC. Above, the wind comes from northwest. After 1500 UTC the model represents the directions measured by the virtual tower. This coincides with growing wind speeds from 2 to $5 \mathrm{~m} \mathrm{~s}^{-1}$ (see Fig. 7). After sunset (dotted line), both the model and the measurement show a shift in the wind direction from northeast to east, and in the second half of the night, to south. During night time a shallow nocturnal boundary layer develops. It is characterized by mostly westerly wind direction and very low wind speeds. The nocturnal boundary layer grows to a depth of about $110 \mathrm{~m}$ in the model and $150 \mathrm{~m}$ in the measurement during the second half of the night. The height of the nocturnal boundary layer is again determined by using the method described in section $3 \mathrm{a}$.

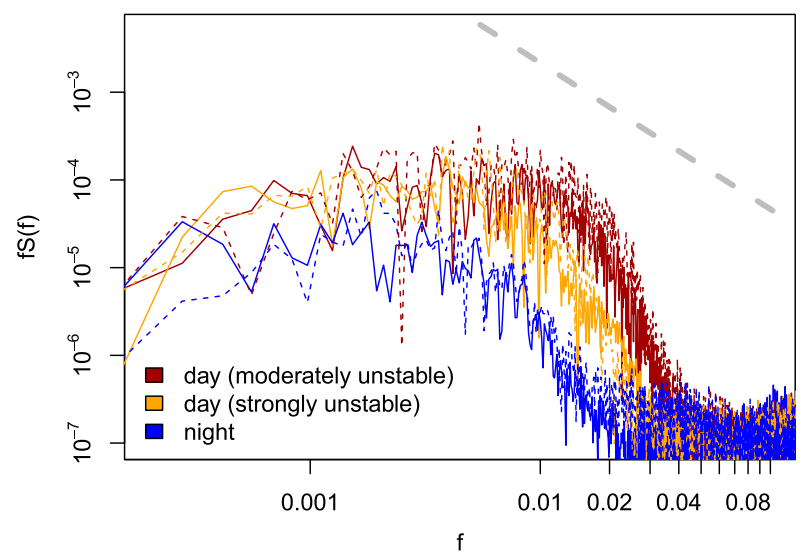

FIG. 5. Spectra of horizontal (solid lines) and vertical (dashed lines) wind speeds for periods of strongly convective, moderately convective, and stable (night) periods. Values are taken from 15 vertical levels down from the average boundary layer height over a period of $2 \mathrm{~h}$. The gray dashed line is $f^{-5 / 3}$.

After sunrise (dashed line) the differences between model and measurement are largest: The observations show that the nocturnal boundary layer starts to transition into the daytime boundary layer after 0600 UTC near the ground with residuals remaining at around $200 \mathrm{~m}$ above ground. After the disappearance of the residuals the boundary layer becomes well mixed again with homogeneous directions (east) over the whole column. The model does not capture the growth of the nocturnal boundary layer up to the measured depth during night and simulates wind from south during the morning with a region of shear at $1000 \mathrm{~m}$ MSL. Starting at around 1100 UTC, the agreement between model and measurement improves. Both show a well-mixed boundary layer with wind coming from northwest with increasing wind speeds during that time. During the evening, both show a shift from north over east to south. In the model this happens gradually, whereas the changes in directions are very distinct in the measurements. In both cases, a new shallow nocturnal boundary layer develops.

As can be seen in Fig. 7 the most prominent feature of the measurements of wind speeds is the low-level jet (LLJ; e.g., Stull 1988) during the first night at around $900 \mathrm{~m}$ MSL. It coincides with the top of the stable nocturnal boundary layer and is characterized by high wind speeds in relatively low heights. In many cases it is faster than the geostrophic wind above. The speed shown here grows immediately after sunset to $5 \mathrm{~m} \mathrm{~s}^{-1}$. It reaches its maximum at 2300 UTC at just below $8 \mathrm{~m} \mathrm{~s}^{-1}$ with a vertical extent shrinking from almost 400 to $100 \mathrm{~m}$. The jet comes exclusively from the east and disappears suddenly at 2300 UTC, while the wind direction is shifting to the south. WRF-LES does capture the phenomenon of the LLJ, but the representation is 
a WRF

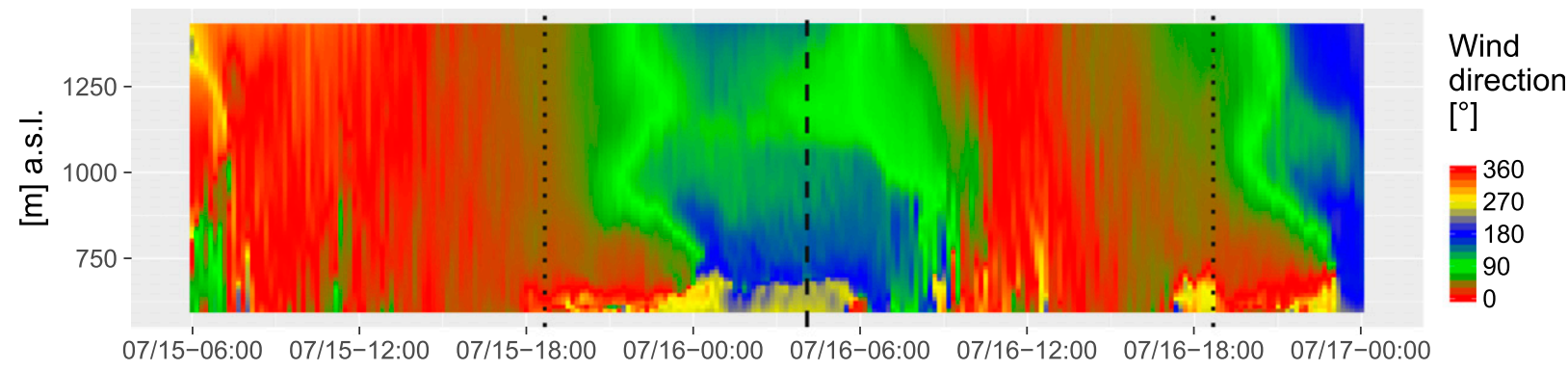

b VirtualTower

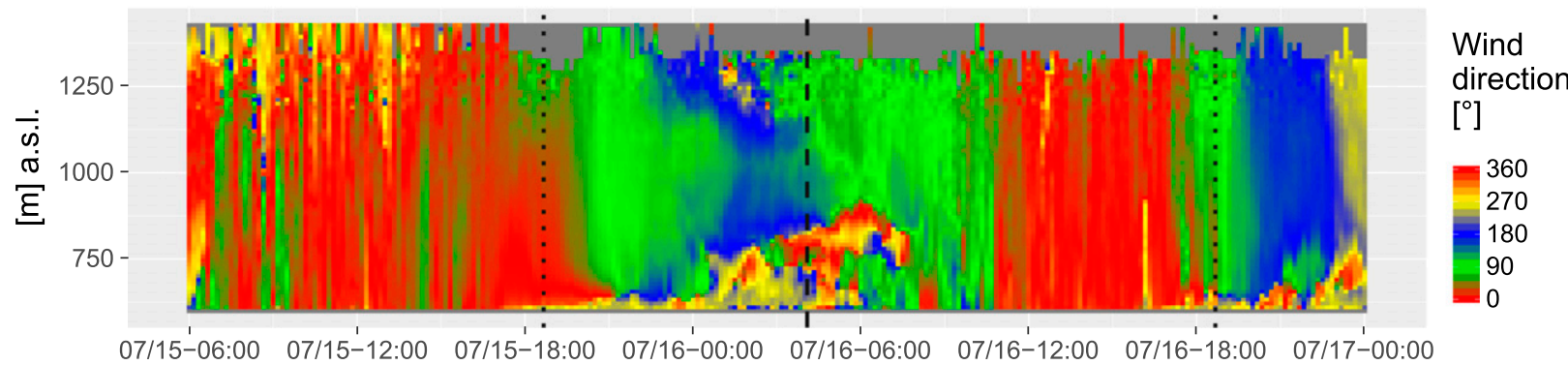

FIG. 6. Wind directions from (a) WRF-LES and (b) the virtual tower for the 2015 simulation period. Model data are taken from four grid points in a $2 \times 2$ pattern and horizontally averaged. Values are temporally averaged to 10 -min means. Virtual tower data are linearly interpolated to model levels. Dashed lines: sunrise; dotted lines: sunset. Time steps are on the $x$ axis; heights above sea level are on the $y$ axis. Values of direction are color coded; values that are not available because of the limited measurement height of the virtual tower are dark gray.

insufficient. The simulated jet appears before sunset with the maximum approximately $5 \mathrm{~h}$ early and $200 \mathrm{~m}$ higher. The vertical extent is strongly exaggerated and the maximum wind speeds are underestimated by about $2 \mathrm{~m} \mathrm{~s}^{-1}$. Because of the shift in time, the simulated jet appears to come from northeast. A less pronounced LLJ can be found during the second night. The representation in the model shows the same shortcomings in timing, height, and vertical extent as during the first occurrence.

The reason for the misrepresentation of the LLJ in the model data is the representation of the LLJ in the reanalysis data used as boundary conditions. The LLJ is not a local phenomenon and is not created within the domain. In the reanalysis data used as boundary conditions the temporal and vertical resolutions are not high enough. The ERA-Interim reanalysis uses 38 vertical levels up to a height of $50 \mathrm{~km}$. No sign of the LLJ is visible in the boundary conditions for 1200 UTC 15 July 2015 , but it is clearly visible as higher wind speeds in the boundary conditions for the next time step at 1800 UTC. They reach $5.7 \mathrm{~m} \mathrm{~s}^{-1}$ in the fourth level at $820 \mathrm{~m} \mathrm{MSL}$ and 5.5 and $4 \mathrm{~m} \mathrm{~s}^{-1}$ in the sixth and seventh levels (1060 and $1300 \mathrm{~m} \mathrm{MSL).}$ The fifth level at $930 \mathrm{~m}$ MSL and those above the seventh and below the fourth show lower speeds of $3 \mathrm{~m} \mathrm{~s}^{-1} .1800$ UTC is exactly the time at which the LLJ appears in the simulated data, as can be seen in Fig. 7a. It also explains the vertical stretching, caused by the high wind speeds in the reanalysis from 820 to $1300 \mathrm{~m}$ MSL and the lower maximum wind speeds of the simulated LLJ relative to those observed, caused by maximum wind speeds of $6.1 \mathrm{~m} \mathrm{~s}^{-1}$ in the reanalysis. In the next set of boundary conditions that is applied at 0000 UTC 16 July 2015, no signs of the LLJ are present in the data and the wind speeds in all essential vertical levels are below $3 \mathrm{~m} \mathrm{~s}^{-1}$. For a proper representation of the LLJ in WRF-LES, boundary conditions with a high temporal resolution, for example hourly, and a high vertical $(<100 \mathrm{~m})$ resolution are required.

The temporal course of the vertical wind speeds (not shown) behaves as expected: during day and actively incoming solar radiation the 10 -min averaged vertical wind speeds easily reach $\pm 2 \mathrm{~m} \mathrm{~s}^{-1}$ with alternating up- and downdrafts at the virtual tower location. After sunset the vertical motions are quickly dampened and stay below $\pm 0.5 \mathrm{~m} \mathrm{~s}^{-1}$. Directly after sunrise the turbulence starts as weak, and it takes another $3 \mathrm{~h}$ to reach the strength and vertical extent of the day before.

Density plots of the three discussed variables (wind direction and horizontal and vertical wind speed) in Fig. 8 give a broader picture. They show only time steps and heights at which both model data and measurement 

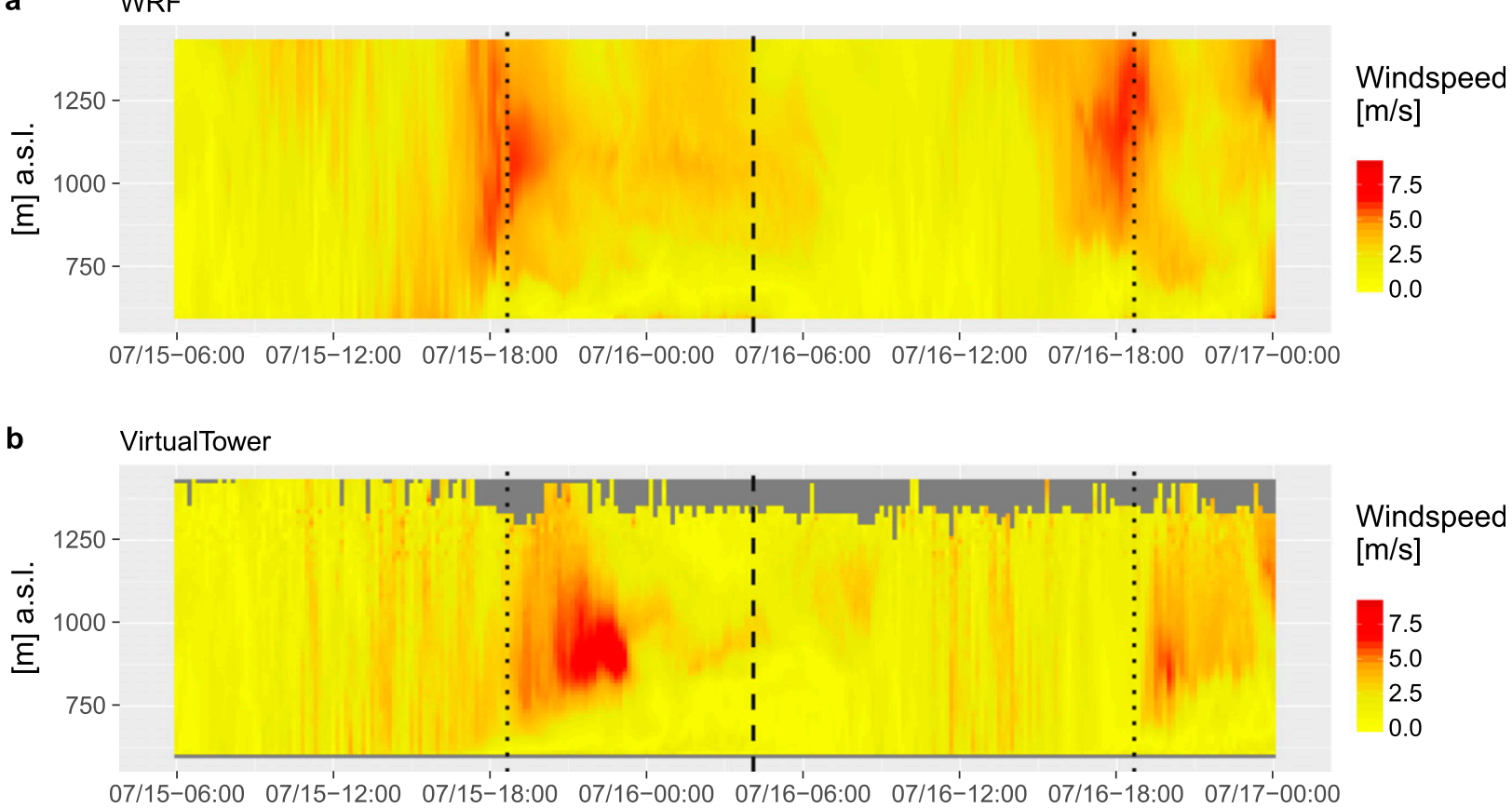

FIG. 7. Wind speeds from (a) WRF-LES and (b) the virtual tower for the 2015 simulation period.

data are available. The direction is simulated well; model and measurement show a distinct maximum around north. The secondary maximum at $100^{\circ}$ in the measurements is shifted toward south in the model Westerly directions are rare in measurement and model. The distributions of the horizontal wind speeds (Fig. 8b) show two distinct features: the bulk of the wind speeds are slightly overestimated by the model (the limit for the first quantile in the model is $1.69 \mathrm{~m} \mathrm{~s}^{-1}$; that measured is $1.33 \mathrm{~m} \mathrm{~s}^{-1}$ ) while the maximum wind speeds are underestimated. These maximum wind speeds in the measurements $\left(7.83 \mathrm{~m} \mathrm{~s}^{-1}\right)$ occur in the center of the LLJ that is, as described above, insufficiently represented in the model. The maximum wind speed in the model reaches $6.23 \mathrm{~m} \mathrm{~s}^{-1}$. The simulated vertical wind speeds (Fig. 8c) show a clear mean close to zero $\left(-0.05 \mathrm{~m} \mathrm{~s}^{-1}\right)$, matching the theory of turbulence according to which vertical motions will average to zero over a sufficiently long time period. The mean of the measured values deviates from 0 and has a value of $-0.15 \mathrm{~m} \mathrm{~s}^{-1}$, hinting at possible surface inhomogeneities that favor downdrafts at the location. The model cannot represent this. Both distributions of vertical wind speeds are skewed toward negative values. This is to be expected, since within one convective structure the area on which air rises is small relative to the area on which it sinks. If these structures pass by the virtual tower with the horizontal wind speed, the device will measure downdrafts for a longer time than updrafts.
The comparable period for the 2016 model covers $32 \mathrm{~h}$ from 1600 UTC 6 July to 0000 UTC 8 July and therefore contains two sunsets and one sunrise. Both measurement and simulation show high wind speeds of up to $6 \mathrm{~m} \mathrm{~s}^{-1}$ (Fig. 9) coming from the north (Fig. 10) before the first sunset. These high wind speeds were the reason for the required smaller model time step of the 2016 model in comparison to the 2015 model. The high wind speeds disappear during the first nighttime hours in the measurements, while a shallow nocturnal boundary layer develops. Simulated wind speeds diminish about one hour earlier. During the second half of the night, directions shift from north over east to south while the wind speeds are low. The model captures this shift very well in timing and vertical extent. It also hints at an area of shear between 1000 and $1200 \mathrm{~m}$ MSL that cannot be validated by the measurements. Both model and measurement show a growth of the nocturnal boundary layer depth during nighttime, while its maximum depth is again underestimated by the model. After sunrise the largest differences in the wind directions can be found. While the measurements show the dissipation of the nocturnal boundary layer due to beginning convection and northwesterly directions within the residuals, the model shows an extension of the conditions above the nocturnal boundary layer down to the ground with southerly directions. The position of the area of shear sinks down accordingly. It has to be noted that the 
determination of a wind direction from the horizontal wind components during times of low wind speeds, as they can be found here, are less reliable. Starting at 0900 UTC 7 July 2016, the agreement between model and measurement improves again. Both show northeasterly wind directions and growing wind speeds. The measured layer of the atmosphere is well mixed up to the maximum measurement height. After the second sunset the directions in model and measurement agree well, both showing the here often found pattern of a shift from north over east to south. The wind speeds, however, show the model limitation already mentioned in the 2015 data: the LLJ occurring between 800 and $1000 \mathrm{~m}$ MSL after sunset is misrepresented by the model. Here it again occurs earlier and before sunset and the vertical extent is exaggerated. Because of the shift in time, the direction of the LLJ (east) is also not represented in the simulation.

The repeating pattern of northerly wind direction during the day and southerly direction during night, which is observed during both simulation periods, is a consequence of the alpine pumping (Lugauer and Winkler 2005; Graf et al. 2016). This process is represented in the simulation, despite being a mesoscale phenomenon. While its origin is present neither in the boundary conditions nor in the LES itself, its modification of the wind field is existent in the reanalysis data. This shows that mesoscale influences are only then absent in the simulation if both the origin and the effect of the phenomenon are not representable on boundary condition or LES scales.

Conditions for the vertical wind speed are very similar to the 2015 model period. During the day, updrafts and downdrafts reach up to $\pm 2 \mathrm{~m} \mathrm{~s}^{-1}$. After sunset the vertical motions disappear, first near the ground while the air above the forming nocturnal boundary layer is still in motion, later over the whole column. After sunrise it takes about three hours until the high vertical speeds are reached again.

The density plots (Fig. 11) for the three measured and simulated variables show a similar picture as in the 2015 model period: directions (Fig. 11a) are mostly north. The secondary maximum of the simulated values at south represents the mismatch between model and measurement just after sunrise on 7 July 2016 (Fig. 10). The two conclusions made from the wind speed data of the 2015 simulation hold true for 2016: the bulk amount of wind speeds is overestimated by the model (the limit for the first quantile in the model is $1.51 \mathrm{~m} \mathrm{~s}^{-1}$; that measured is $1.23 \mathrm{~m} \mathrm{~s}^{-1}$ ) and maximum wind speeds are underestimated: the model values only reach $5.2 \mathrm{~m} \mathrm{~s}^{-1}$ whereas speeds up to $6.59 \mathrm{~m} \mathrm{~s}^{-1}$ were measured during the simulation period. Figure $11 \mathrm{c}$, showing the a
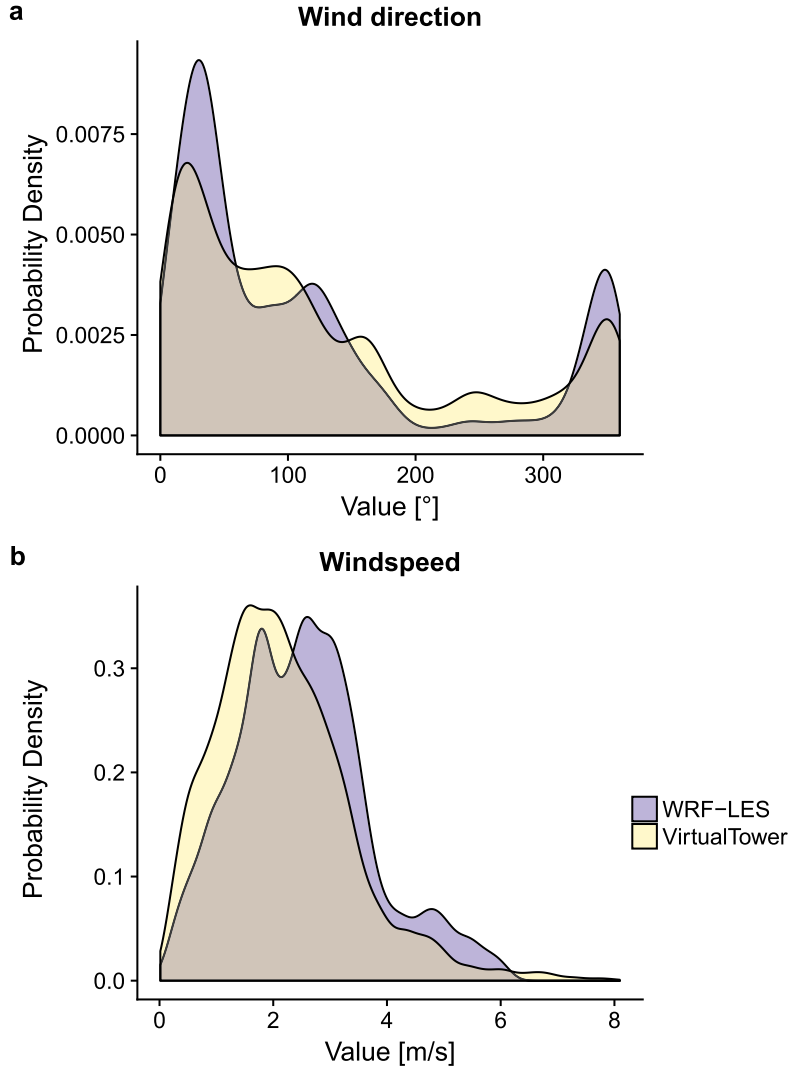

c

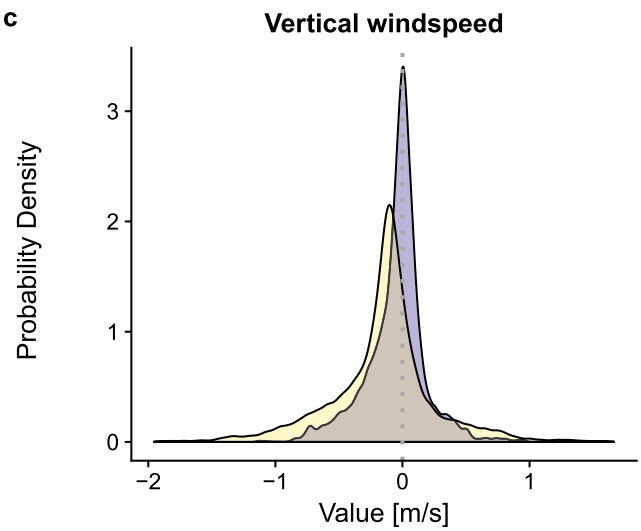

FIG. 8. Density plots of measured and simulated values for (a) wind direction, (b) horizontal wind speed, and (c) vertical wind speed from the 2015 simulation period.

distributions of the vertical wind speeds, also confirms the findings from the 2015 model: the mean of the measured values is strongly negative $\left(-0.25 \mathrm{~m} \mathrm{~s}^{-1}\right)$ as compared with the simulation mean of $-0.04 \mathrm{~m} \mathrm{~s}^{-1}$. Both distributions are skewed toward negative values.

\section{c. Additional value of model output compared to measurements}

Considering the small size of the domain it is possible that WRF-LES with the setup described above primarily 
a WRF

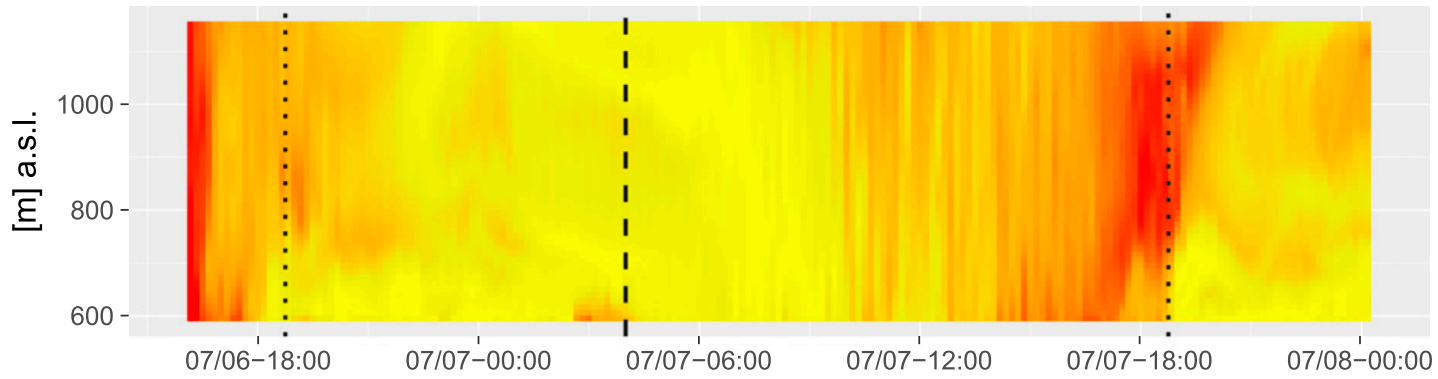

Windspeed $[\mathrm{m} / \mathrm{s}]$

b VirtualTower

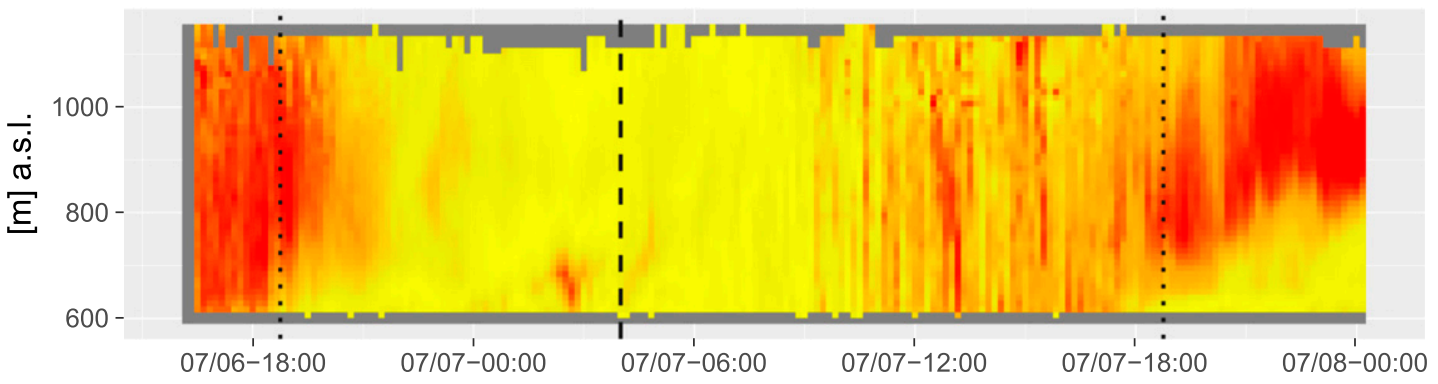

Windspeed $[\mathrm{m} / \mathrm{s}]$

FIG. 9. Wind speeds from (a) WRF-LES and (b) the virtual tower for the 2016 simulation period.

mixes the values prescribed by the boundary conditions with little connection to the actual properties of the selected area. To disprove this possibility, a phenomenon within the model data has to be found that is spatially or temporally so confined that it cannot originate from the boundary conditions. One such phenomenon can be seen on 0210 UTC 7 July 2016, at which time the measured wind speeds close to the ground are increasing from $<2$ to $5 \mathrm{~m} \mathrm{~s}^{-1}$ for 50 min (Fig. 9b). The phenomenon reaches $150 \mathrm{~m}$ in height. The wind is

a

a WRF

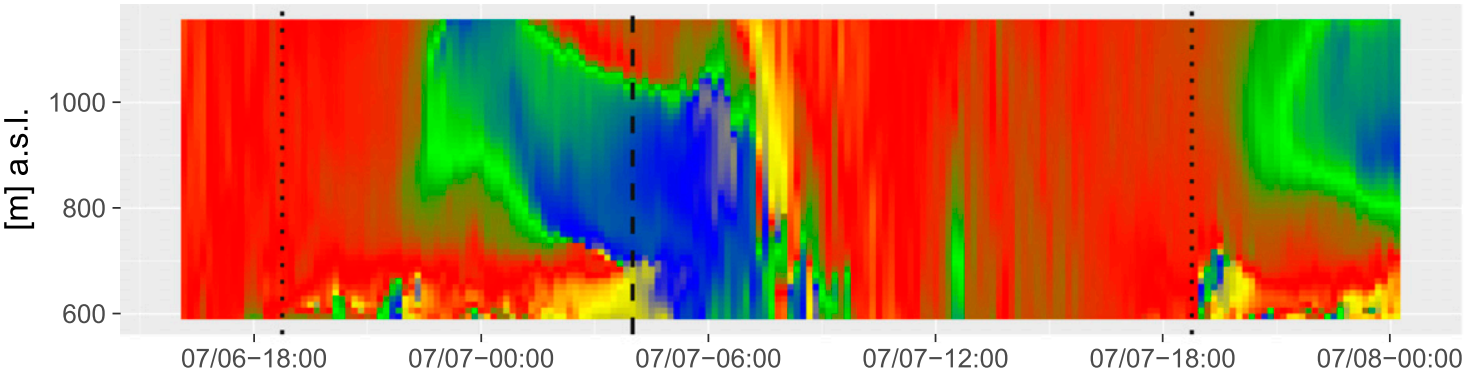

b VirtualTower

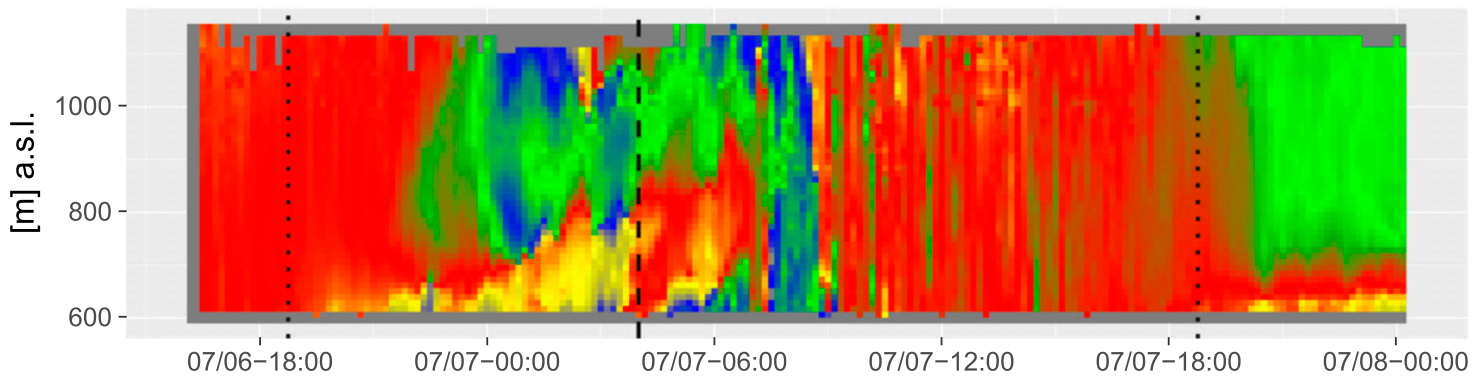

FIG. 10. Wind directions from (a) WRF-LES and (b) the virtual tower for the 2016 simulation period. 
coming from the west (Fig. 10b). A similar phenomenon is visible in the model data during the same time. The duration is overestimated $(90 \mathrm{~min}$ from 0230 to 0400 UTC), while height $(70 \mathrm{~m})$ and value of the wind speed $\left(4 \mathrm{~m} \mathrm{~s}^{-1}\right)$ are underestimated. During the high wind speeds in the model, the wind direction is also west, as seen in the measurements. This phenomenon is not represented in the boundary conditions and has therefore to originate from the local conditions. Measurements during other times have proven that this phenomenon occurs regularly, always shortly before sunrise and especially during summer. With just the point or column measurements the origin cannot be reconstructed. Here, the four-dimensional output of the model is a useful tool.

Figure 12 shows simulated wind speed data during the time of the phenomenon described above. Each panel shows an area of $3.5 \mathrm{~km}$ by $3.5 \mathrm{~km}$ surrounding the virtual tower (white spot in the center). Just west of the virtual tower, the western ridge (see Fig. 1b) is indented by a small valley from west to east. Starting at 0130 UTC the conditions seen in Fig. 12a begin to develop: a significant flow from the mountain in the southwestern corner of the domain brings excess air toward the small valley. This forms a pool of cold air with a vertical extent of over $50 \mathrm{~m}$ on the ridge west of the virtual tower, illustrated by the blue layer of relatively cold air on the left side of Fig. 13a. The air here is up to $4 \mathrm{~K}$ colder than the average $\left(9^{\circ} \mathrm{C}\right)$ over the observed area up to $850 \mathrm{~m}$ MSL and the horizontal wind speed is below $1 \mathrm{~m} \mathrm{~s}^{-1}$. The cold air leaves the ridge through the valley and accelerates on the plain. Data from the vertical wind speeds show constantly negative values of up to $-0.6 \mathrm{~m} \mathrm{~s}^{-1}$ on the steepest part of the slope during the whole second half of the night. This in turn also increases the horizontal wind speeds near the ground. On the plain the flow is deflected toward the south (Figs. 12a-c) in accordance with the wind direction just above the nocturnal boundary layer measured at the time (cf. Fig. 10). Because of this deflection, the flow is not measured by the virtual tower until later.

In the following hours (Figs. 12d-f) the deflection is weakened and the flow takes a more straight western direction. It is during that time that the virtual tower measures increasing wind speeds in low heights. It is also the time in which the vertical extent of the flow reaches its maximum at about $70 \mathrm{~m}$, whereas it was more shallow before. Simultaneously, the depth of the cold air reservoir on top of the ridge shrinks to below $10 \mathrm{~m}$ and the deviations from the temperature mean are reduced from $-3.2^{\circ}$ to $-2.7^{\circ} \mathrm{C}$ (Figs. $13 \mathrm{~d}-\mathrm{f}$, marked by the depth of the blue layer on the left side of the a

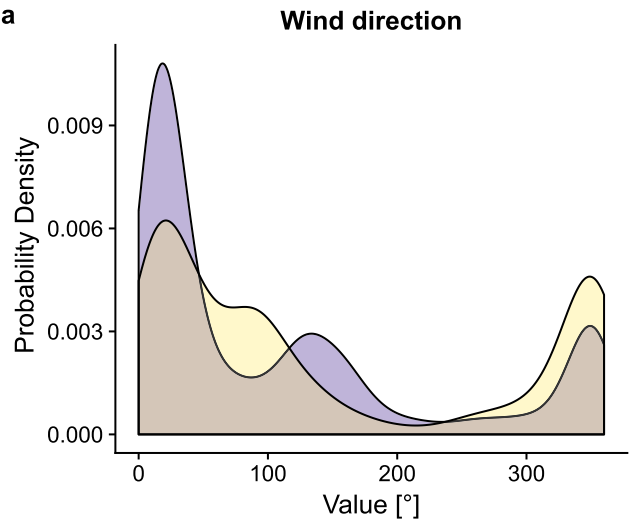

b Windspeed

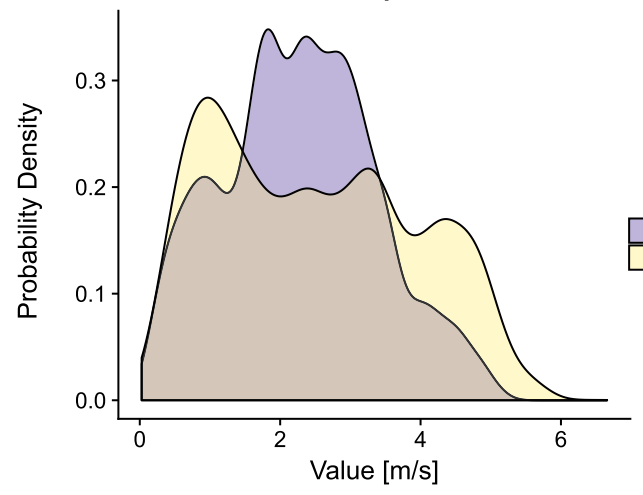

c

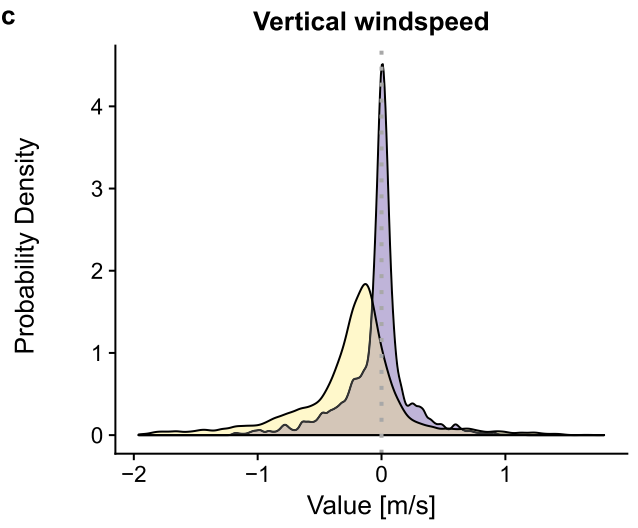

FIG. 11. As in Fig. 8, but from the 2016 simulation period.

panels). The diminishing gradient is a hint that the cold pool is no longer replenished by flow from the mountain.

Soon after, the deflection takes an opposite sign and gives the flow a northward component (Fig. 12g), making it pass by the virtual tower to the north. Vertical wind speeds during this time on the slope are still negative, but take an absolute lower value of $-0.1 \mathrm{~m} \mathrm{~s}^{-1}$. The virtual tower only measures this flow during a short moment in its transition from a southward to a northward deflection. Soon afterward, the sunrise dissolves the temperature gradient on the western hill (visible as 

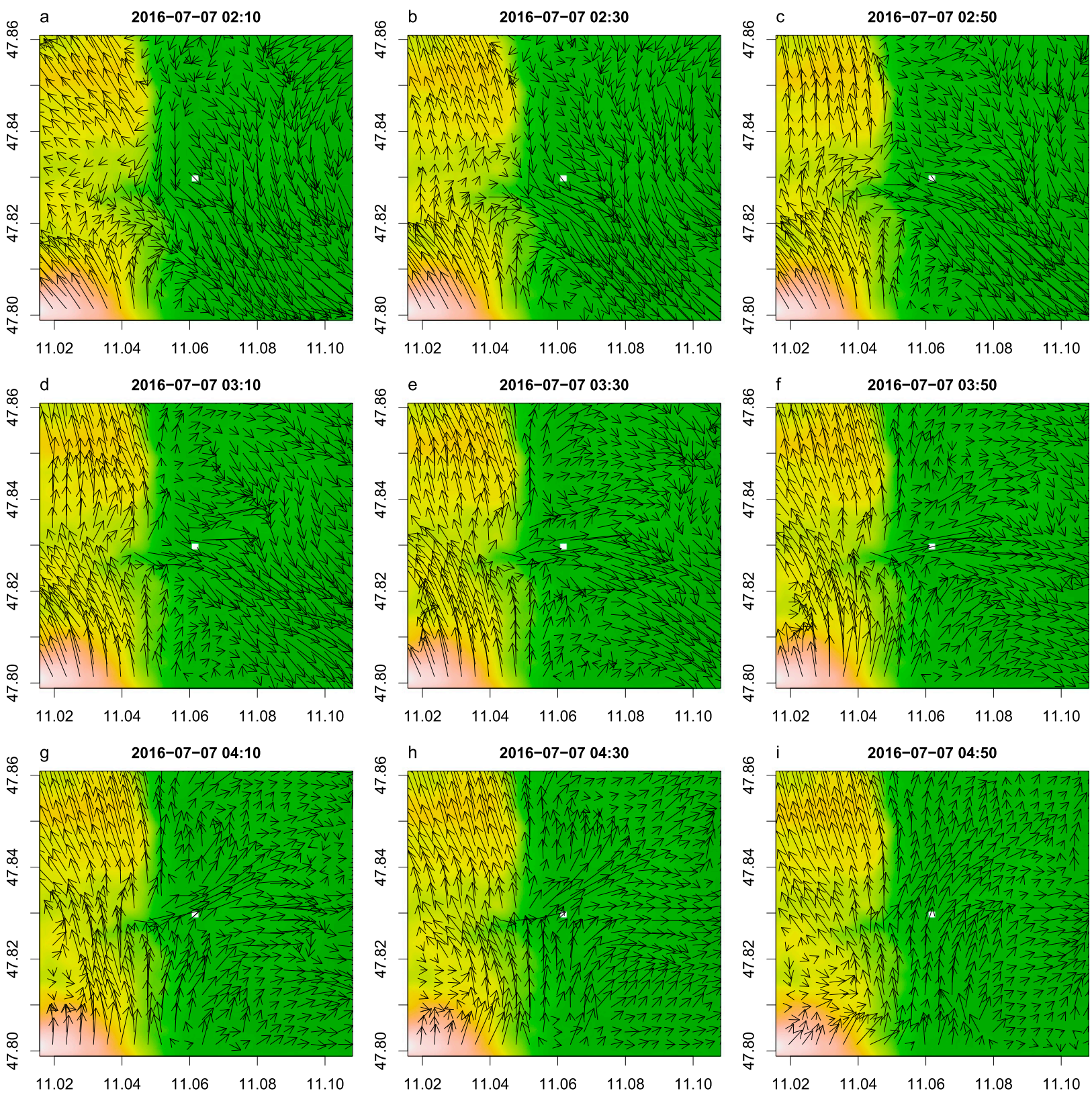

FIG. 12. Temporal development of the flow passing the virtual tower (marked by the white dot) in the early morning of 7 Jul 2016. Arrows are scaled by the wind speed. Speed data are averaged over four vertical levels between 33 and $66 \mathrm{~m}$ above ground.

the more and more shallow blue layer on the ridge in Figs. 13g-i), stops the katabatic flows (Figs. 12h,i), and causes the flow in the plain to vanish. The temperature deviations on the hill drop to $-1^{\circ} \mathrm{C}$ in the last two time steps shown (Figs. 13h,i).

If the measured spike in wind speeds really is the result of the described katabatic flow would have to be determined by additional measurements, but the results show that the model data can easily be used to identify possible drivers, while requiring much less effort than measurement campaigns. To analyze such micrometeorological events, the used simulation has to be run in a very high resolution: the horizontal resolution has to be fine enough to resolve the fine gradients in the elevation model and the vertical resolution has to have enough levels close to the ground that the shown strong temperature gradients can be resolved. LES are the only approach for this scale at the moment: the parameterizations that mesoscale models depend on cannot be used in such high resolution and direct numerical 

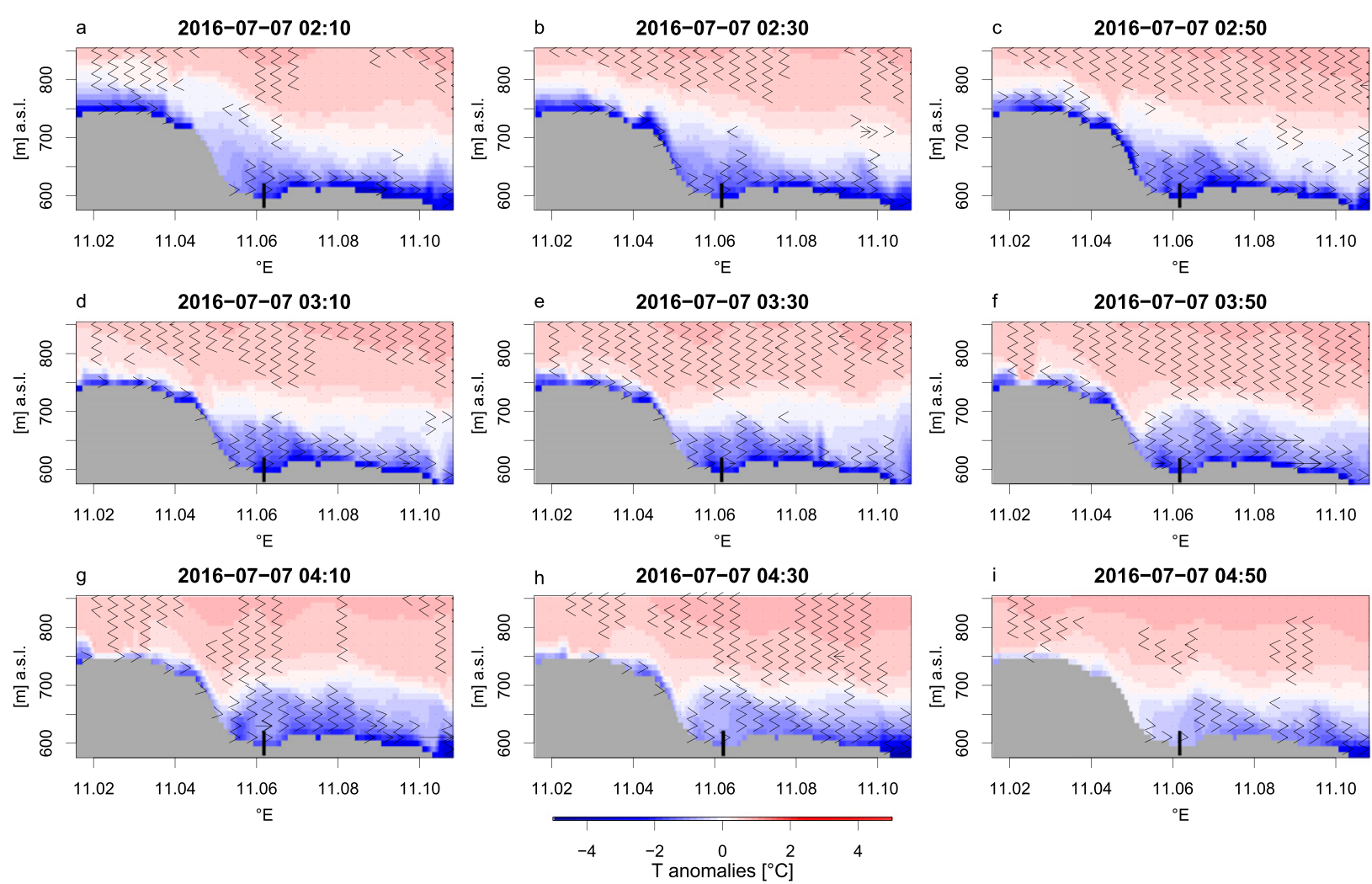

FIG. 13. Temporal development of the potential temperature deviations for the time steps shown in Fig. 12. The deviations are calculated from the mean of all data points shown in the nine panels (temporal and spatial averaging). The cut is from west to east, passing through the position of the virtual tower (the black bar on the $x$ axis).

simulations are computationally too expensive for an area the size of this.

\section{Summary and conclusions}

The study shows the setup and the application of WRF in LES mode for a real domain with realistic initial and boundary conditions, using high-resolution land use and elevation maps and meteorological data from reanalysis. The LES domain was driven directly by the boundary conditions without further nesting, resulting in a setup that uses considerably less computing power than comparable nested setups.

LES and especially the employed subgrid-scale model need a high vertical resolution for reliable results. This high resolution together with the terrain following coordinates used by WRF leads to challenges: steep slopes can easily cause violations of the Courant-Friedrichs-Lewy condition (Courant et al. 1967) and therefore disrupt the simulation. Shorter time steps and smoothing of the input elevation data can be a solution. In general, the setup of a highresolution WRF-LES domain for complex terrain has to be described as a process of trial and error. By changing the position and size of the domain, the distribution of the vertical levels or the time step, a working configuration can eventually be achieved. If instabilities are observed at the domain edges during time steps where new boundary conditions are read, observational nudging toward those conditions can prove helpful. Corresponding experiments showed only marginal differences in the solutions relative to the presented runs without nudging.

The simulations represented the boundary condition mean values. The LES domain is forced by the meteorological drivers, limiting any significant deviation from the boundary conditions, even if they may have occurred between the ingestion intervals in the real-world and limiting the influence of mesoscale phenomena because that scale is not represented. The strong dependence of the LES outcomes on the boundary conditions can be best seen at the transitions at dusk and dawn. For a proper representation of these atmospheric changes, boundary condition updates in higher temporal resolution are necessary. Within the LES domain the model develops typical LES flow structures. Because of the fact that this domain contains slopes, varying soil properties and changing radiation, the exact shape of these 
structures deviates from those produced within idealized LES. The problem of underdeveloped turbulence at the inflow edge of the domain is present, yet can be mitigated by removing affected grid points from the evaluation. As the size of this area depends on horizontal wind speed, this modeling approach is mostly suited for times of average wind speeds $<5 \mathrm{~m} \mathrm{~s}^{-1}$. For higher wind speeds we recommend to expand the domain in the streamwise direction to increase the amount of grid points where turbulence can develop.

The two "ScaleX" (Wolf et al. 2017) campaigns from 2015 and 2016 provide a unique dataset for the evaluation of the model data. In the presented text we compared the model results with the measurements of an innovative measurement system - a virtual tower consisting of three Doppler-lidar devices-that is able to measure the wind components in the boundary layer in high vertical and temporal resolution. When compared with these measurements, the model shows that it is sufficiently able to represent the meteorological conditions of the area. Simulated patterns in wind speed and direction are in accordance with the measurements. Weaknesses are in the representation of the nocturnal boundary layer height, which is underestimated in the model, and the LLJs, which are insufficiently represented in the boundary conditions.

The most promising approach for improving the modeling setup is the use of boundary conditions with a higher resolution, especially temporal. Ideally, these boundary conditions are downscaled online by nesting the LES-domain in mesoscale domains, yet this increases the required computing time substantially. The vertical nesting capabilities of the newer WRF versions might be a big step in this direction.

The presented single-domain approach should be applicable to all kinds of states of the atmospheric boundary layer, even to stable conditions when the grid is refined sufficiently. It is beneficial to have a priori knowledge about the governing macro and mesoscale influences of the area of interest to ensure those are present in the boundary conditions. Accordingly, the approach might not be suited for areas with, for example, mountain and valley breezes or lake breezes, because these can be too small in size to be represented in the boundary conditions, depending on the resolution of the selected product.

The fact that WRF-LES simulated the locally and temporarily confined phenomenon of increased wind speeds in low heights due to assumed katabatic flows at night shows that the described modeling approach is able to produce local phenomena that are not present in the boundary conditions. For such cases the output of a model is a valuable addition to measurements. Because of its four-dimensional structure, it can provide information about spatial or temporal developments. This information can be used in urban management, by identifying and preserving flows of fresh air from the surroundings to improve the air quality. In the case of the presented area, which is characterized by dairy farming, the information can be used to build stables in a way that minimizes the odor nuisance for neighboring residential areas. Around airports, the data from realistic LES could be used to identify hot spots where strong turbulent motions develop, improving flight safety. With increasing computing power these applications are well within reach and the lower computational costs of the approach presented here even allows for studies on all kinds of weather conditions.

Acknowledgments. This work was partially funded by an MICMoR scholarship. MICMoR is the Helmholtz Research School for Mechanisms and Interactions of Climate Change in Mountain Regions. Matthias Zeeman was supported by the German Research Foundation (DFG; Project ZE1006/2-1). The Terrestrial Environmental Observatory (TERENO) pre-Alpine infrastructure is funded by the Helmholtz Association and the Federal Ministry of Education and Research. We thank the Scientific Team of ScaleX Campaign 2016 for their contribution.

\section{REFERENCES}

Aitken, M. L., B. Kosović, J. D. Mirocha, and J. K. Lundquist, 2014: Large eddy simulation of wind turbine wake dynamics in the stable boundary layer using the Weather Research and Forecasting Model. J. Renewable Sustain. Energy, 6, 033137, https://doi.org/10.1063/1.4885111.

Andren, A., A. R. Brown, P. J. Mason, J. Graf, U. Schumann, C.-H. Moeng, and F. T. Nieuwstadt, 1994: Large-eddy simulation of a neutrally stratified boundary layer: A comparison of four computer codes. Quart. J. Roy. Meteor. Soc., 120, 1457-1484, https://doi.org/10.1002/qj.49712052003.

Basu, S., and A. Lacser, 2017: A cautionary note on the use of Monin-Obukhov similarity theory in very high-resolution large-eddy simulations. Bound.-Layer Meteor., 163, 351-355, https://doi.org/10.1007/s10546-016-0225-y.

_ stratified atmospheric boundary layer turbulence: A scaledependent dynamic modeling approach. J. Atmos. Sci., 63, 2074-2091, https://doi.org/10.1175/JAS3734.1.

Beare, R. J., 2008: The role of shear in the morning transition boundary layer. Bound.-Layer Meteor., 129, 395-410, https:// doi.org/10.1007/s10546-008-9324-8.

— , and Coauthors, 2006: An intercomparison of large-eddy simulations of the stable boundary layer. Bound.-Layer Meteor., 118, 247-272, https://doi.org/10.1007/s10546-0042820-6.

Bou-Zeid, E., C. Meneveau, and M. B. Parlange, 2004: Large-eddy simulation of neutral atmospheric boundary layer flow over heterogeneous surfaces: Blending height and effective surface 
roughness. Water Resour. Res., 40, W02505, https://doi.org/ 10.1029/2003WR002475.

—_, J. Overney, B. D. Rogers, and M. B. Parlange, 2009: The effects of building representation and clustering in largeeddy simulations of flows in urban canopies. Bound.-Layer Meteor., 132, 415-436, https://doi.org/10.1007/s10546-0099410-6.

Catalano, F., and C.-H. Moeng, 2010: Large-eddy simulation of the daytime boundary layer in an idealized valley using the Weather Research and Forecasting numerical model. Bound.-Layer Meteor., 137, 49-75, https://doi.org/10.1007/ s10546-010-9518-8.

Chow, F. K., and R. L. Street, 2009: Evaluation of turbulence closure models for large-eddy simulation over complex terrain: Flow over Askervein Hill. J. Appl. Meteor. Climatol., 48, 1050-1065, https://doi.org/10.1175/2008JAMC1862.1.

Chu, X., L. Xue, B. Geerts, R. Rasmussen, and D. Breed, 2014: A case study of radar observations and WRF LES simulations of the impact of ground-based glaciogenic seeding on orographic clouds and precipitation. Part I: Observations and model validations. J. Appl. Meteor. Climatol., 53, 2264-2286, https://doi.org/10.1175/JAMCD-14-0017.1.

CLC, 2000: Corine land cover $100 \mathrm{~m}$, version 5. European Environment Agency Copernicus Land Monitoring Service, https://land.copernicus.eu/pan-european/corine-land-cover/ clc-2000.

Courant, R., K. Friedrichs, and H. Lewy, 1967: On the partial difference equations of mathematical physics. IBM J. Res. Develop., 11, 215-234, https://doi.org/10.1147/rd.112.0215.

Crosman, E. T., and J. D. Horel, 2012: Idealized large-eddy simulations of sea and lake breezes: Sensitivity to lake diameter, heat flux and stability. Bound.-Layer Meteor., 144, 309-328, https://doi.org/10.1007/s10546-012-9721-x.

Daniels, M. H., K. A. Lundquist, J. D. Mirocha, D. J. Wiersema, and F. K. Chow, 2016: A new vertical grid nesting capability in the Weather Research and Forecasting (WRF) Model. Mon. Wea. Rev., 144, 3725-3747, https://doi.org/10.1175/ MWR-D-16-0049.1.

Deardorff, J. W., 1970: A three-dimensional numerical investigation of the idealized planetary boundary layer. Geophys. Astrophys. Fluid Dyn., 1, 377-410, https://doi.org/ 10.1080/03091927009365780.

_- 1972: Numerical investigation of neutral and unstable planetary boundary layers. J. Atmos. Sci., 29, 91-115, https://doi.org/ 10.1175/1520-0469(1972)029<0091:NIONAU>2.0.CO;2.

ECMWF, 2009: ERA-Interim Project (updated monthly). Research Data Archive, National Center for Atmospheric Research Computational and Information Systems Laboratory, https://doi.org/10.5065/D6CR5RD9.

Etling, D., and R. Brown, 1993: Roll vortices in the planetary boundary layer: A review. Bound.-Layer Meteor., 65, 215-248, https://doi.org/10.1007/BF00705527.

Graf, M., M. Kossmann, K. Trusilova, and G. Mühlbacher, 2016: Identification and climatology of alpine pumping from a regional climate simulation. Front. Earth Sci., 4, 5, https:// doi.org/10.3389/feart.2016.00005.

Hattori, Y., C.-H. Moeng, H. Hirakuchi, S. Ishihara, S. Sugimoto, and H. Suto, 2010: Numerical simulation of turbulence structures in the neutral atmospheric surface layer with a mesoscale meteorological model, WRF. Proc. Fifth Int. Symp. on Computational Wind Engineering (CWE 2010), Chapel Hill, NC, Computational Wind Engineering, 385.
Hong, S.-Y., J. Dudhia, and S.-H. Chen, 2004: A revised approach to ice microphysical processes for the bulk parameterization of clouds and precipitation. Mon. Wea. Rev., 132,103-120, https://doi.org/10.1175/1520-0493(2004) $132<0103$ :ARATIM $>2.0$. CO;2.

Huang, J., and E. Bou-Zeid, 2013: Turbulence and vertical fluxes in the stable atmospheric boundary layer. Part I: A large-eddy simulation study. J. Atmos. Sci., 70, 1513-1527, https://doi.org/ 10.1175/JAS-D-12-0167.1.

Iacono, M. J., J. S. Delamere, E. J. Mlawer, M. W. Shephard, S. A. Clough, and W. D. Collins, 2008: Radiative forcing by longlived greenhouse gases: Calculations with the AER radiative transfer models. J. Geophys. Res., 113, D13103, https://doi.org/ 10.1029/2008JD009944.

Kaimal, J. C., and J. J. Finnigan, 1994: Atmospheric Boundary Layer Flows: Their Structure and Measurement. Oxford University Press, 289 pp.

Kosović, B., 1997: Subgrid-scale modelling for the large-eddy simulation of high-Reynolds-number boundary layers. J. Fluid Mech., 336, 151-182, https://doi.org/10.1017/ S0022112096004697.

— quasi-steady, stably stratified atmospheric boundary layer. J. Atmos. Sci., 57, 1052-1068, https://doi.org/10.1175/15200469(2000)057<1052:ALESSO > 2.0.CO;2.

Lang, M., A. Gohm, and J. Wagner, 2015: The impact of embedded valleys on daytime pollution transport over a mountain range. Atmos. Chem. Phys., 15, 11981-11998, https://doi.org/ 10.5194/acp-15-11981-2015.

LeMone, M. A., 1973: The structure and dynamics of horizontal roll vortices in the planetary boundary layer. J. Atmos. Sci., 30, 1077-1091, https://doi.org/10.1175/1520-0469(1973)030<1077: TSADOH $>2.0 . \mathrm{CO} ; 2$.

Lugauer, M., and P. Winkler, 2005: Thermal circulation in South Bavaria-Climatology and synoptic aspects. Meteor. Z., 14, 15-30, https://doi.org/10.1127/0941-2948/2005/0014-0015.

Lundquist, K. A., F. Chow, and J. Lundquist, 2010: Numerical errors in flow over of steep topography: Analysis and alternatives. 14th Conf. on Mountain Meteorology, Olympic Valley, CA, Amer. Meteor. Soc., 10.1, https://ams.confex.com/ams/ 14MountMet/techprogram/paper_173801.htm.

Mirocha, J., J. K. Lundquist, and B. Kosović, 2010: Implementation of a nonlinear subfilter turbulence stress model for large-eddy simulation in the Advanced Research WRF Model. Mon. Wea. Rev., 138, 4212-4228, https://doi.org/10.1175/2010MWR3286.1.

— G. Kirkil, E. Bou-Zeid, F. K. Chow, and B. Kosović, 2013: Transition and equilibration of neutral atmospheric boundary layer flow in one-way nested large-eddy simulations using the Weather Research and Forecasting Model. Mon. Wea. Rev., 141, 918-940, https://doi.org/10.1175/MWR-D-11-00263.1.

_ B. Kosović, and G. Kirkil, 2014: Resolved turbulence characteristics in large-eddy simulations nested within mesoscale simulations using the Weather Research and Forecasting Model. Mon. Wea. Rev., 142, 806-831, https://doi.org/10.1175/ MWR-D-13-00064.1.

Moeng, C.-H., 1984: A large-eddy-simulation model for the study of planetary boundary-layer turbulence. J. Atmos. Sci., 41, 2052-2062, https://doi.org/10.1175/1520-0469(1984)041<2052: ALESMF $>2.0 . \mathrm{CO} ; 2$.

1986: Large-eddy simulation of a stratus-topped boundary layer. Part I: Structure and budgets. J. Atmos. Sci., 43, 2886-2900, https://doi.org/10.1175/1520-0469(1986) $043<2886$ :LESOAS $>2.0$. CO; 2 . 
_ - J. Dudhia, J. Klemp, and P. Sullivan, 2007: Examining twoway grid nesting for large eddy simulation of the PBL using the WRF Model. Mon. Wea. Rev., 135, 2295-2311, https://doi.org/ 10.1175/MWR3406.1.

Muñoz-Esparza, D., and B. Kosović, 2018: Generation of inflow turbulence in large-eddy simulations of non-neutral atmospheric boundary layers with the cell perturbation method. Mon. Wea. Rev., 146, 1889-1909, https://doi.org/10.1175/ MWR-D-18-0077.1.

_ _ _ C. García-Sánchez, and J. van Beeck, 2014a: Nesting turbulence in an offshore convective boundary layer using large-eddy simulations. Bound.-Layer Meteor., 151, 453-478, https://doi.org/10.1007/s10546-014-9911-9.

,$- \ldots$, J. Mirocha, and J. van Beeck, 2014b: Bridging the transition from mesoscale to microscale turbulence in numerical weather prediction models. Bound.-Layer Meteor. 153, 409-440, https://doi.org/10.1007/s10546-014-9956-9.

_ J. K. Lundquist, J. A. Sauer, B. Kosović, and R. R. Linn, 2017: Coupled mesoscale-LES modeling of a diurnal cycle during the CWEX-13 field campaign: From weather to boundarylayer eddies. J. Adv. Model. Earth Syst., 9, 1572-1594, https:// doi.org/10.1002/2017MS000960.

National Aeronautics and Space Administration and Japan's Ministry of Economy, Trade, and Industry, 2009: ASTER global digital elevation model. NASA EOSDIS Land Processes DAAC, https://doi.org/10.5067/ASTER/ASTGTM.002.

Newman, J. F., T. A. Bonin, P. M. Klein, S. Wharton, and R. K. Newsom, 2016: Testing and validation of multi-lidar scanning strategies for wind energy applications. Wind Energy, 19, 2239-2254, https://doi.org/10.1002/we.1978.

Nieuwstadt, F. T., P. J. Mason, C.-H. Moeng, and U. Schumann, 1993: Large-eddy simulation of the convective boundary layer: A comparison of four computer codes. Turbulent Shear Flows 8, F. Durst et al., Eds., Springer, 343-367.

Nunalee, C. G., B. Kosović, and P. E. Bieringer, 2014: Eulerian dispersion modeling with WRF-LES of plume impingement in neutrally and stably stratified turbulent boundary layers. Atmos. Environ., 99, 571-581, https://doi.org/10.1016/ j.atmosenv.2014.09.070.

Rai, K., L. K. Berg, B. Kosović, J. D. Mirocha, M. S. Pekour, and W. J. Shaw, 2017: Comparison of measured and numerically simulated turbulence statistics in a convective boundary layer over complex terrain. Bound.-Layer Meteor., 163, 69-89, https://doi.org/10.1007/s10546-016-0217-y.

Saiki, E. M., C.-H. Moeng, and P. P. Sullivan, 2000: Large-eddy simulation of the stably stratified planetary boundary layer.
Bound.-Layer Meteor., 95, 1-30, https://doi.org/10.1023/ A:1002428223156.

Siebesma, A. P., and Coauthors, 2003: A large eddy simulation intercomparison study of shallow cumulus convection. J. Atmos. Sci., 60, 1201-1219, https://doi.org/10.1175/15200469(2003)60<1201:ALESIS>2.0.CO;2.

Skamarock, W., and Coauthors, 2008: A description of the Advanced Research WRF version 3. NCAR Tech. Note NCAR/TN-475+STR, 113 pp., https://doi.org/10.5065/D68S4MVH.

Stawiarski, C., K. Träumner, C. Knigge, and R. Calhoun, 2013: Scopes and challenges of dual-Doppler lidar wind measurements-An error analysis. J. Atmos. Oceanic Technol., 30, 2044-2062, https://doi.org/10.1175/JTECH-D-12-00244.1.

Stull, R. B., 1988: An Introduction to Boundary Layer Meteorology. Kluwer Academic, 666 pp.

Sullivan, P. P., C.-H. Moeng, B. Stevens, D. H. Lenschow, and S. D. Mayor, 1998: Structure of the entrainment zone capping the convective atmospheric boundary layer. J. Atmos. Sci., 55, 3042-3064, https://doi.org/10.1175/1520-0469(1998) 055<3042:SOTEZC $>2.0 . \mathrm{CO} ; 2$

Talbot, C., E. Bou-Zeid, and J. Smith, 2012: Nested mesoscale large-eddy simulations with WRF: Performance in real test cases. J. Hydrometeor., 13, 1421-1441, https://doi.org/10.1175/ JHM-D-11-048.1.

Vasiljević, N., and Coauthors, 2017: Perdigão 2015: Methodology for atmospheric multi-Doppler lidar experiments. Atmos. Meas. Tech., 10, 3463-3483, https://doi.org/10.5194/amt-103463-2017.

Wagner, J., A. Gohm, and M. Rotach, 2015: The impact of valley geometry on daytime thermally driven flows and vertical transport processes. Quart. J. Roy. Meteor. Soc., 141, 17801794, https://doi.org/10.1002/qj.2481.

Wolf, B., and Coauthors, 2017: The ScaleX campaign: Scalecrossing land surface and boundary layer processes in the TERENO-preAlpine Observatory. Bull. Amer. Meteor. Soc., 98, 1217-1234, https://doi.org/10.1175/BAMS-D-15-00277.1.

Xue, L., X. Chu, R. Rasmussen, D. Breed, and B. Geerts, 2016: A case study of radar observations and WRF LES simulations of the impact of ground-based glaciogenic seeding on orographic clouds and precipitation. Part II: AgI dispersion and seeding signals simulated by WRF. J. Appl. Meteor. Climatol., 55, 445464, https://doi.org/10.1175/JAMC-D-15-0115.1.

Yamaguchi, T., and G. Feingold, 2012: Technical note: Large-eddy simulation of cloudy boundary layer with the Advanced Research WRF Model. J. Adv. Model. Earth Syst., 4, M09003, https:// doi.org/10.1029/2012MS000164. 